\title{
Movement, drivers and bimodality of the South Asian High
}

\author{
Matthias Nützel, Martin Dameris, and Hella Garny \\ Deutsches Zentrum für Luft- und Raumfahrt, Institut für Physik der Atmosphäre, Oberpfaffenhofen, Germany \\ Correspondence to: Matthias Nützel (matthias.nuetzel@dlr.de)
}

Received: 27 April 2016 - Published in Atmos. Chem. Phys. Discuss.: 2 June 2016

Revised: 19 October 2016 - Accepted: 11 November 2016 - Published: 25 November 2016

\begin{abstract}
The South Asian High (SAH) is an important component of the summer monsoon system in Asia. In this study we investigate the location and drivers of the $\mathrm{SAH}$ at $100 \mathrm{hPa}$ during the boreal summers of 1979 to 2014 on interannual, seasonal and synoptic timescales using seven reanalyses and observational data. Our comparison of the different reanalyses focuses especially on the bimodality of the SAH, i.e. the two preferred modes of the SAH centre location: the Iranian Plateau to the west and the Tibetan Plateau to the east. We find that only the National Centers for Environmental Prediction-National Center of Atmospheric Research (NCEP-NCAR) reanalysis shows a clear bimodal structure of the SAH centre distribution with respect to daily and pen$\operatorname{tad}(5$ day) mean data. Furthermore, the distribution of the SAH centre location is highly variable from year to year. As in simple model studies, which connect the SAH to heating in the tropics, we find that the mean seasonal cycle of the $\mathrm{SAH}$ and its centre are dominated by the expansion of convection in the South Asian region $\left(70-130^{\circ} \mathrm{E} \times 15-30^{\circ} \mathrm{N}\right)$ on the south-eastern border of the SAH. A composite analysis of precipitation and outgoing long-wave radiation data with respect to the location of the SAH centre reveals that a more westward (eastward) location of the SAH is related to stronger (weaker) convection and rainfall over India and weaker (stronger) precipitation over the western Pacific.
\end{abstract}

\section{Introduction}

The South Asian High (SAH) or Asian (summer) monsoon anticyclone is one of the most pronounced circulation patterns in the Northern Hemisphere (NH) (Mason and Anderson, 1963) and emerges through diabatic heating in the South Asian monsoon region (Gill, 1980; Hoskins and Rodwell, 1995) during boreal summer. Horizontally, the SAH covers large parts of southern Asia and the Middle East (black contours in Fig. 1). It is located on the edge of the tropics and subtropics, vertically spanning from around 300 to $70 \mathrm{hPa}$ (see Fig. 2 in Randel and Park, 2006), i.e. approximately the whole upper troposphere and lower stratosphere (UTLS) region. Despite the closed anticyclonic flow often shown in climatological analysis, the circulation system exhibits strong variability in strength and location (Hsu and Plumb, 2000; Popovic and Plumb, 2001; Garny and Randel, 2013; Ploeger et al., 2015; Vogel et al., 2015).

Apart from the highly variable synoptic behaviour of the $\mathrm{SAH}$, Zhang et al. (2002) found that the longitudinal distribution of the SAH centre location - as identified by the geopotential height maximum along the ridgeline (see green line in Fig. 1a) - is bimodal. Using pentad (5 day) mean data, they have found two preferred modes of the $\mathrm{SAH}$ at $100 \mathrm{hPa}$ and have coined the terms Iranian Mode (IM) and Tibetan Mode (TM) according to the two peaks (at 55-65 and 82.5$92.5^{\circ} \mathrm{E}$ respectively) of the bimodal distribution (see cyan bars in Fig. 1a).

This bimodality has been attributed to the so-called warm preference of the SAH (i.e. the SAH centre is located on top of an anomalously warm air column in the troposphere; see Fig. 2 in Randel and Park, 2006), and Zhang et al. (2002) argued that the TM corresponds to diabatic heating of the Tibetan Plateau (TP) and the IM corresponds to adiabatic heating in the free troposphere and diabatic heating of the Iranian Plateau (IP). This heat preference is also supported by Qian et al. (2002), who focus on the seasonal variation of the $\mathrm{SAH}$, referring to the high pressure system that moves to the western Pacific during winter (see also Zhou et al., 2006 and references therein).

Consequently, following studies seized the suggestion of this bimodality (e.g. Zhou et al., 2009; Zarrin et al., 2010; Yan et al., 2011), while others (Garny and Randel, 2013; 

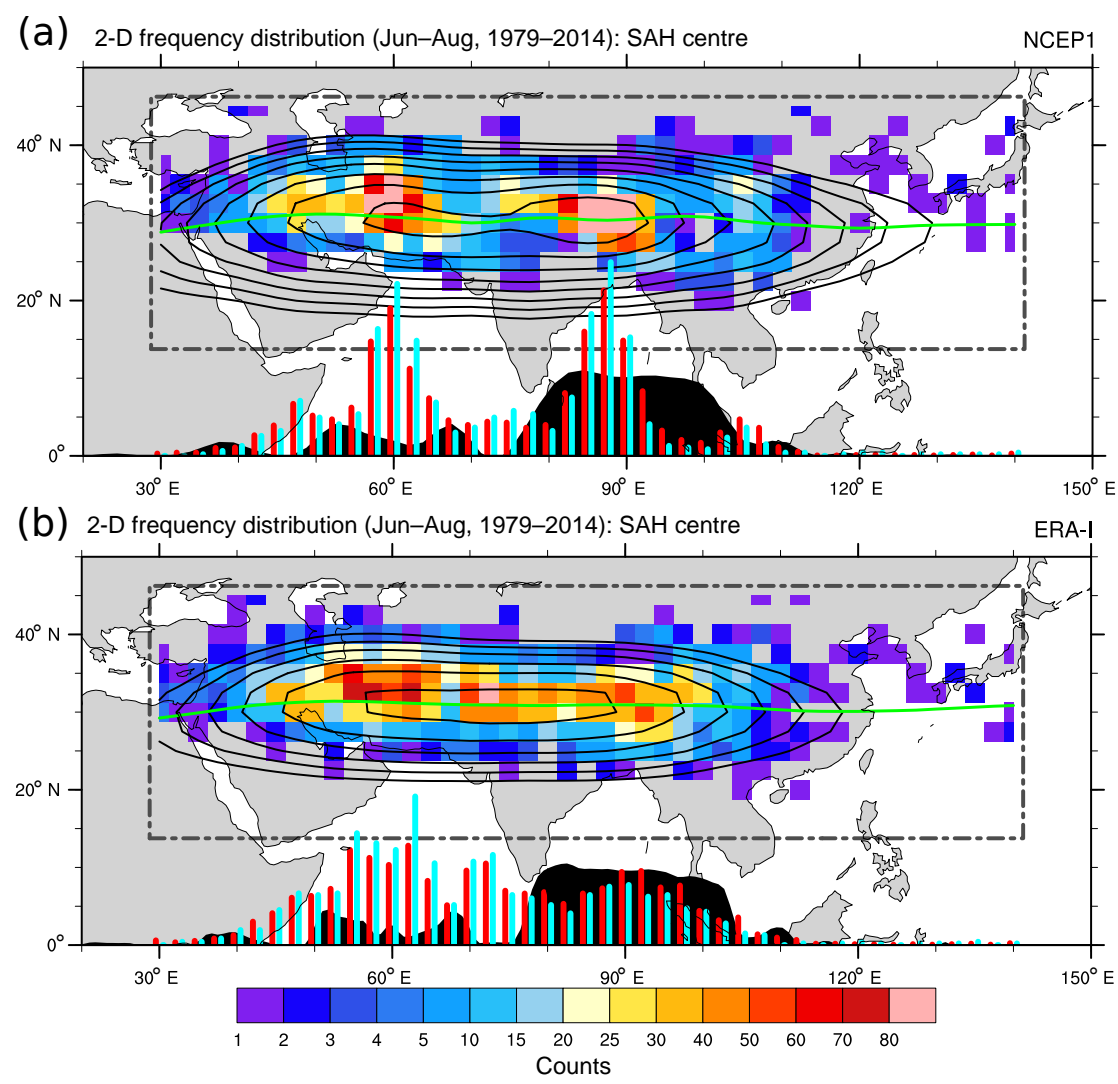

Figure 1. (a, b) Colour shading indicates the two-dimensional frequency of occurrence of the SAH centre at $100 \mathrm{hPa}$ as diagnosed by (a) NCEP-1 and (b) ERA-I over June to August 1979-2014 based on daily values $\left(2.5^{\circ} \times 2.5^{\circ}\right.$ bins; note the non-linear colour scale). The box marked by the grey dashed line indicates the range of the data that are used to diagnose the centre. Black contours show the long-term seasonal (JJA, 1979-2014) mean of the geopotential height (contour levels starting at $16.72 \mathrm{~km}$ and a spacing of $15 \mathrm{~m}$ ) and the green line shows the long-term mean location of the ridgeline (zero zonal wind) at $100 \mathrm{hPa}$. On the longitude axis, black shading indicates (a) NCEP1 orography (at T62 resolution) and (b) ERA-I orography $\left(0.75^{\circ}\right.$ resolution $\sim$ ERA-I native resolution) at $\sim 31.5^{\circ} \mathrm{N}$ (approximately the ridgeline), with $1^{\circ}$ corresponding to $500 \mathrm{~m}$. Red (cyan) bars indicate the one-dimensional PDF (bins of $2.5^{\circ}$ ) of the daily location of the SAH centre over the June-August (July-August) period 1979-2014 (1980-1994) with $2^{\circ}$ corresponding to $1 \%$.

Ploeger et al., 2015) tried to link their results to this finding (see details in Sect. 2.2). The classification of the SAH into two modes has also found its way into textbooks on the monsoon system (e.g. Yanai and $\mathrm{Wu}, 2006$; Xu and Zhang, 2008; Wu et al., 2008; Zhang and Zhi, 2010).

In this study we investigate the location and movement of the $\mathrm{SAH}$ at $100 \mathrm{hPa}$, with particular focus on the bimodality, by employing seven reanalyses, including four highresolution (model resolution $<1^{\circ}$ ) reanalysis data sets. A deeper understanding of the SAH has two major impact areas: first, on the regional scale the location of the SAH was found to be connected to precipitation anomalies in Asia (flood-drought areas) and was found to be a predictor of monsoonal spills (see Zhang et al., 2002, and references therein). Second, on the global scale, the SAH features trace gas anomalies, e.g. of CO (Li et al., 2005; Park et al., 2009), $\mathrm{H}_{2} \mathrm{O}$ (Randel and Park, 2006), HCN (Randel et al., 2010), HCFC22 (Chirkov et al., 2016) and $\mathrm{O}_{3}$ (Randel and Park,
2006), which can ultimately reach the stratosphere (Dethof et al., 1999; Randel et al., 2010). Recent studies have successfully demonstrated the impact of the Asian summer monsoon on the composition of the extratropical lower stratosphere over Europe as measured during the TACTS/ESMVal (2012) campaign (Vogel et al., 2014; Müller et al., 2016; Vogel et al., 2016). Consequently, detailed knowledge of the location and movement of the SAH is necessary to be able to understand how trace gas anomalies build up and to quantify the amount of trace gases injected into stratosphere. Because in situ measurements at UTLS levels in the Asian monsoon and neighbouring regions are sparse, aircraft measurement campaigns have been specifically designed to investigate transport processes within the anticyclone and consequent outflow from the anticyclone (OMO, 2015; StratoClim, 2016/2017).

The questions we want to address in this study are (1) is there bimodality of the SAH centre location at $100 \mathrm{hPa}$ ? 
(2) How can the "climatological" bimodality be connected to the movement on synoptic timescales? (3) What causes the movement of the SAH on a synoptic, seasonal and climatological basis?

The remainder of this paper is structured as follows: in Sect. 2, we present the data and methods used in this study. Sect. 3 deals with question (1). Questions (2) and (3) are addressed in Sects. 4 and 5. Finally, we discuss our results in Sect. 6 and end with a conclusion (Sect. 7).

\section{Data and method}

\subsection{Data}

For our analyses we employ data from different reanalyses and observations. Our investigation focuses on the NH summer seasons during 1979-2014.

\subsubsection{Reanalysis data}

The seven reanalyses we are using in this study are: (1) the NCEP/NCAR Reanalysis 1 (NCEP-1) from the National Centers of Environmental Prediction (NCEP) and the National Center of Atmospheric Research (NCAR), (2) NCEP/DOE Reanalysis 2 (NCEP-2) from NCEP and the Department of Energy (DOE), (3) the Climate Forecast System Reanalysis (CFSR) from NCEP, (4) the Japanese 25-year reanalysis (JRA-25) from the Japan Meteorological Agency (JMA) and the Central Research Institute of Electric Power Industry (CRIEPI), (5) the 55-year reanalysis (JRA55) from JMA, (6) the ERA-Interim reanalysis (ERA-I) from the European Centre for Medium-Range Weather Forecasts (ECMWF) and (7) the Modern-Era Retrospective Analysis (MERRA) from the National Aeronautics and Space Administration (NASA). Further specifications of these reanalysis data sets are shown in Table 1, including information about the model resolution, assimilation scheme, data source and the corresponding references.

The data used in this study cover the NH summer seasons from 1979 to 2014 (1979 to 2010 for CFSR and from 1979 to 2013 for JRA-25). Meteorological fields (geopotential height, wind and surface temperature) of all reanalysis data sets have been used with the provided resolution of $2.5^{\circ} \times 2.5^{\circ}$, except for MERRA, which has been regridded from the native resolution $\left(0.5^{\circ}\right.$ latitude by $0.67^{\circ}$ longitude) to a $2.5^{\circ} \times 2.5^{\circ}$ grid. The daily data used for the detection of the SAH centre were obtained from the $6 \mathrm{~h}$ values of the reanalyses by simple averaging. Likewise, pentad mean data and monthly mean data are calculated from the daily data.

\subsubsection{Observational data}

We use outgoing long-wave radiation (OLR) as a proxy for convective activity. In this study OLR is obtained from the daily gridded interpolated OLR data from NOAA (Na- tional Oceanic and Atmospheric Administration) (Liebman and Smith, 1996). The data set has a resolution of $2.5^{\circ} \times 2.5^{\circ}$ and covers the period June 1974 to December 2013.

Additionally, we use the Global Precipitation Climatology Project (GPCP) Version 2.2 combined precipitation data set (Adler et al., 2003). This data set combines satellite and rain gauge measurements to create a global precipitation field on a $2.5^{\circ} \times 2.5^{\circ}$ grid with monthly temporal resolution. The time period covered is from January 1979 to present. For daily precipitation data we employ Version 1.2 of the $1^{\circ} \times 1^{\circ}$ daily GPCP data set (Huffman et al., 2001), which covers the period from October 1996 to present.

As a measure of the Indian summer monsoon (ISM) strength we include the official all-India monsoon rainfall time series, i.e. the all-India rainfall index (AIRI), from the India Meteorological Department (IMD). This monthly time series covers the monsoon period (JuneSeptember) from 1901 to 2013 and was obtained from the IMD web site at http://www.imd.gov.in/section/nhac/ dynamic/Monsoon_frame.htm.

The seasonal (3-month running mean) Niño 3.4 index based on the Extended Reconstructed Sea Surface Temperature (ERSST) Version 4 data set (Huang et al., 2015; Liu et al., 2015; Huang et al., 2016) from NOAA with a base period of 1981-2010 used to measure the El Niño-Southern Oscillation (ENSO) was provided by NOAA's CPC (Climate Prediction Center) from their website: http://www.cpc.ncep. noaa.gov/data/indices/.

\subsection{Method}

To locate the centre of the SAH we use the method described by Zhang et al. (2002), which consists of two steps: first, based on daily, pentad, monthly or seasonal data from June to August (1979-2014) at $100 \mathrm{hPa}$ the ridgeline is identified as the location of the minimum of the absolute zonal wind field at each longitude (see green line in Fig. 1a) in the area $15-45^{\circ} \mathrm{N} \times 30-140^{\circ} \mathrm{E}$ (box marked by the grey dashed line in Fig. 1a). Second, along this ridgeline the maximum of the daily, pentad, monthly or seasonal geopotential field at $100 \mathrm{hPa}$ is determined.

This results in a (lat, long) coordinate, which represents the centre of the SAH for the respective day, pentad, month or season. For analyses with respect to pentad means, only data from 3 June to 31 August are used to get 18 "full" pentads per summer period. The analysis based on seasonal mean (JJA) data results in one centre location of the SAH for each year.

We note that in a first test phase identifying the centre of the SAH only via the maximum of geopotential in the area $15-45^{\circ} \mathrm{N} \times 30-140^{\circ} \mathrm{E}$ gave comparable probability distribution functions (PDFs) of the SAH centre location. However, all analyses in this study are based on the two step method (i.e. detection of the ridgeline followed by determination of the maximum geopotential height along the ridgeline). We use this method as it has been applied in the majority of 
Table 1. Overview of the reanalysis data employed in this study.

\begin{tabular}{|c|c|c|c|c|}
\hline & CFSR & ERA-I & JRA-25 & JRA-55 \\
\hline Reference & Saha et al. (2010) & Dee et al. (2011) & Onogi et al. (2007) & Kobayashi et al. (2015) \\
\hline Institution & NCEP & ECMWF & JMA-CRIEPI & JMA \\
\hline \multicolumn{5}{|l|}{ Resolution } \\
\hline horizontal & $\mathrm{T} 382^{\mathrm{a}}\left(\sim 0.5^{\circ} \times 0.5^{\circ}\right)$ & $\mathrm{T} 255\left(\sim 0.7^{\circ} \times 0.7^{\circ}\right)$ & $\mathrm{T} 106\left(\sim 1.1^{\circ} \times 1.1^{\circ}\right)$ & TL319 ${ }^{\mathrm{b}}(\sim 55 \mathrm{~km})$ \\
\hline vertical (top) & $\mathrm{L} 64^{\mathrm{c}}(\sim 0.3 \mathrm{hPa})$ & $\mathrm{L} 60(0.1 \mathrm{hPa})$ & $\mathrm{L} 40(0.4 \mathrm{hPa})$ & L60 (0.1 hPa) \\
\hline Assimilation & 3D-Var & 4D-Var & 3D-Var & 4D-Var \\
\hline Data source & rda.ucar.edu & apps.ecmwf.int & rda.ucar.edu & rda.ucar.edu \\
\hline \multirow[t]{2}{*}{ Period } & Jan 1979-Dec 2010 & Jan 1979-present & Jan 1979-Jan 2014 & Jan 1958-present \\
\hline & MERRA & NCEP-1 & NCEP-2 & \\
\hline Reference & Rienecker et al. (2011) & Kalnay et al. (1996) & Kanamitsu et al. (2002) & \\
\hline Institution & NASA & NCEP-NCAR & NCEP-DOE & \\
\hline \multicolumn{5}{|l|}{ Resolution } \\
\hline horizontal & $0.5^{\circ} \times 0.67^{\circ}$ & $\mathrm{T} 62\left(\sim 1.9^{\circ} \times 1.9^{\circ}\right)$ & $\mathrm{T} 62\left(\sim 1.9^{\circ} \times 1.9^{\circ}\right)$ & \\
\hline vertical (top) & L72 (0.01 hPa) & $\mathrm{L} 28(3 \mathrm{hPa})$ & $\mathrm{L} 28(3 \mathrm{hPa})$ & \\
\hline Assimilation & 3D-Var & 3D-Var & 3D-Var & \\
\hline Data source & mirador.gsfc.nasa.gov & esrl.noaa.gov & rda.ucar.edu & \\
\hline Period & Jan 1979-present & Jan 1948-present & Jan 1979-present & \\
\hline
\end{tabular}

Table 2. Overview of studies addressing bimodality. Geopotential height and zonal wind are denoted by $\phi$ and $u$ respectively. For details see Sect. 2.2.

\begin{tabular}{|c|c|c|c|c|c|}
\hline Study & Data set & Period & Time step & Variables & Method \\
\hline Zhang et al. (2002) & NCEP-1 & July-August 1980-1994 & pentad & $\phi, u$ at $100 \mathrm{hPa}$ & $\max \phi$ along ridgeline \\
\hline Qian et al. (2002) & NCEP-1 & July-August 1958-1997 & monthly & $\phi, u$ at $100 \mathrm{hPa}$ & $\max \phi$ along ridgeline \\
\hline Zhou et al. (2006) ${ }^{a}$ & NCEP-1 & June-August 1950-1999 & monthly & $\phi$ at $100 \mathrm{hPa}$ & $\max \phi$ \\
\hline Zhou et al. (2009) ${ }^{a}$ & NCEP-1 & July-August 1950-1999 & monthly & $\phi$ at $100 \mathrm{hPa}$ & $\max \phi^{\mathrm{b}}$ \\
\hline Zarrin et al. (2010) ${ }^{\mathrm{a}}$ & NCEP-1 & June-August 1971-2000 & monthly & $\phi$ at $100 / 200 \mathrm{hPa}$ & $\max \phi^{\mathrm{c}}$ \\
\hline Yan et al. (2011) & NCEP-1 & June-August 2005-2009 & daily & $\phi, u$ at $100 \mathrm{hPa}$ & $\max \phi$ along ridgeline \\
\hline Wei et al. (2014) & ERA40 & June-August 1958-2002 & seasonal & $\phi, u$ at $200 \mathrm{hPa}$ & $\max \phi$ along ridgeline $\mathrm{b}^{\mathrm{b}}$ \\
\hline Garny and Randel (2013) & MERRA & May-September 2006 & daily & $\mathrm{PV}$ at $360 / 380 \mathrm{~K}$ & probability via PV threshold \\
\hline Ploeger et al. (2015) & ERA-I & 20 June-20 August 2011 & daily & $\mathrm{PV}$ at $360 / 380 \mathrm{~K}$ & probability via PV threshold \\
\hline
\end{tabular}

${ }^{a}$ Time periods and height levels were restricted to the range where bimodality of the SAH was found in the respective studies. ${ }^{\mathrm{b}}$ Method of centre detection was not specified. The methods in Zhou et al. (2009) and Wei et al. (2014) are probably based on the methods in Zhou et al. (2006) and Zhang et al. (2002) respectively. ${ }^{\mathrm{c}}$ Possibility to detect multiple centres. However, the study does not focus on the monsoon region but investigates anticyclones worldwide.

studies on pressure levels (see Table 2), especially the studies dealing with daily or pentad data. Table 2 summarises the details of studies on the $\mathrm{SAH}$ (centre) location regarding the variables, the methods, the time periods and the timescales used. Apart from Wei et al. (2014), who report a bimodal distribution of the seasonal mean SAH centre location in ERA-40 data on $200 \mathrm{hPa}$, all pressure-level-based studies in Table 2 rely on NCEP- 1 data. These studies comprise the $100 \mathrm{hPa}$ level and report clear bimodality in the distribution of the location of the centre of the SAH during the NH summer months on various timescales. Table 2 includes two potential vorticity (PV)-based analyses on isentropes, which try to draw a connection to the bimodality found on pressure levels. Apart from focusing on isentropes, their method is dis- tinct from the other studies in Table 2. Instead of looking for the centre of the SAH they investigate the occurrence probability of the SAH at a certain grid point. The grid point is covered by the SAH if its PV value is below a certain threshold (e.g. $0.3 \mathrm{PV}$ units at $360 \mathrm{~K}$ or $1.6 \mathrm{PV}$ at $380 \mathrm{~K}$ ). The respective probability is then given as the fraction of time steps where this criterion is met. Furthermore, we note the studies from Zhou et al. $(2006,2009)$ as they also investigate AOGCMs (Atmosphere-Ocean General Circulation Models) with respect to their ability to simulate bimodality in the SAH location on a monthly basis.

As in the studies mentioned before, we focus on the $100 \mathrm{hPa}$ level in our study to be consistent with these previous works. Furthermore, the $100 \mathrm{hPa}$ level is close to the 
tropopause height in the monsoon area, making this level of particular interest regarding stratosphere-troposphere exchange.

\section{Location of the SAH}

\subsection{Different distributions of the $\mathrm{SAH}$ centre in NCEP-1 and ERA-I}

To illustrate the extent of the $\mathrm{SAH}$, which is defined by the strong signatures in the geopotential field, the climatological JJA geopotential height at $100 \mathrm{hPa}$ for the period 1979 2014 is shown in Fig. 1a and b as black contours for NCEP-1 and ERA-I data respectively. For both NCEP-1 and ERA-I the climatological centre of the SAH is located at approximately $60-90^{\circ} \mathrm{E}$ and $30-32.5^{\circ} \mathrm{N}$. The latitudinal location is also indicated by the climatological ridgeline (green line in Fig. 1a and b). Interestingly, NCEP-1 already seems to show two centres in the climatological long-term mean. This is indicated by the squeezed contours at approximately $30^{\circ} \mathrm{N}$, $72.5^{\circ} \mathrm{E}$.

The two-dimensional frequency distribution of the SAH centre based on daily values for the JJA period 1979-2014 is depicted by the colour shading in Fig. 1a and b. For NCEP-1 two clear maxima can be identified, which are collocated with the maxima of the geopotential height climatology, whereas for ERA-I the distribution seems to be more smoothed out over the whole centre region of the SAH.

These features can be more easily identified in the onedimensional PDFs of the SAH centre with respect to its longitudinal location (red bars in Fig. 1). The rather sharp maxima identified by NCEP-1 lie at 60 and $87.5^{\circ} \mathrm{E}$, extend about $\pm 5^{\circ}$ to each side and correspond to the IM and the TM respectively. This terminology corresponds to the location of the maxima over the Iranian and Tibetan plateaus (IP and TP) (orography close to the ridgeline is displayed by black shading in Fig. 1). This double-peak structure is not reproduced by ERA-Interim data, which show the highest values over the IP, but no localised peak over the TP.

Furthermore, at about $70-80^{\circ} \mathrm{E}$ the $\mathrm{SAH}$ centre is scarcely found in NCEP-1 data. This is not the case for ERA-I data, which show a small peak in this region. Fig. 2a and b display the probabilities of the SAH centre to be located in the IM, mid-region (region between IM and TM) and TM region as diagnosed via daily and pentad data (blue and pink bars for ERA-I and NCEP-1) to highlight this difference.

A scatter plot of the daily location of the SAH centre as diagnosed by ERA-I vs. NCEP-1 (Fig. 3) shows where these differences come from. A notable number of samples fall into the TP region for NCEP-1, whereas for ERA-I these samples are spread out over the region $\sim 40-100^{\circ} \mathrm{E}$ (horizontal line in Fig. 3). Conversely, samples that are found in the midregion for ERA-I are spread out over $\sim 60-90^{\circ} \mathrm{E}$ in NCEP-1 (vertical line in Fig. 3).
To verify that the results of our analysis do not depend solely on the time period chosen, we have also calculated the one-dimensional PDFs for July-August 1980-1994 (same period used by Zhang et al., 2002 for the pentad analysis; see Table 2). These PDFs are displayed as cyan bars in Fig. 1a and $b$ and confirm that the general features of the PDFs during the two periods are in qualitative agreement. Moreover, the one-dimensional distributions in Fig. 1a resemble the distributions based on pentad mean data in Zhang et al. (2002) and daily data in Yan et al. (2011) (see details of these studies in Table 2).

The obvious discrepancies between NCEP-1 and ERA-I lead to the questions of where these differences come from and which reanalysis is correct. Possible reasons for the differences will be stated in the discussion (Sect. 6). However, due to the complexity of the reanalysis models and the subsequent data assimilation, we find it difficult to address these questions directly. Hence, we use a set of seven reanalyses to determine the range of results and to see if the SAH exhibits bimodality in the sense of two pronounced (centre) regions over the IP and TP.

\subsection{Coherent analysis of the $\mathrm{SAH}$ centre location in seven reanalyses}

To get a more reliable answer to the question, whether there is bimodality in the location of the SAH, we employ seven reanalysis data sets in a consistent manner. In the following we will show results based on daily, pentad, monthly and seasonal mean data. For all of these timescales bimodality was found in previous studies (see Table 2).

\subsubsection{Climatology of the SAH at $100 \mathrm{hPa}$}

Figure 4 shows the 1979-2014 (1979-2010 and 1979-2013 for CFSR and JRA-25) climatology of geopotential height during the NH summer (JJA) for each of the seven reanalysis data sets together with the mean ridgeline (green dashed line). All reanalyses show the climatological centre of the $\mathrm{SAH}$ in the region $\sim 50-95^{\circ} \mathrm{E}$ and $\sim 25-35^{\circ} \mathrm{N}$ and a mean ridgeline located at approximately $30^{\circ} \mathrm{N}$, with slight differences depending on the reanalysis.

MERRA and NCEP-2 predict the centre region farther to the west than the other reanalyses (Fig. 4c and d). In comparison with ERA-I, JRA-25, JRA-55 and MERRA, the NCEP reanalyses (Fig. 4a and d) show slightly higher geopotential height values, whereas CFSR (Fig. 4g) shows slightly lower geopotential height values. This is not attributable to the different base period for the climatology of CFSR (1979-2010). Differences between ERA-I, JRA-25 and JRA55 with respect to the climatological representation of the SAH (Fig. 4b, e and f) are hardly discernible. 

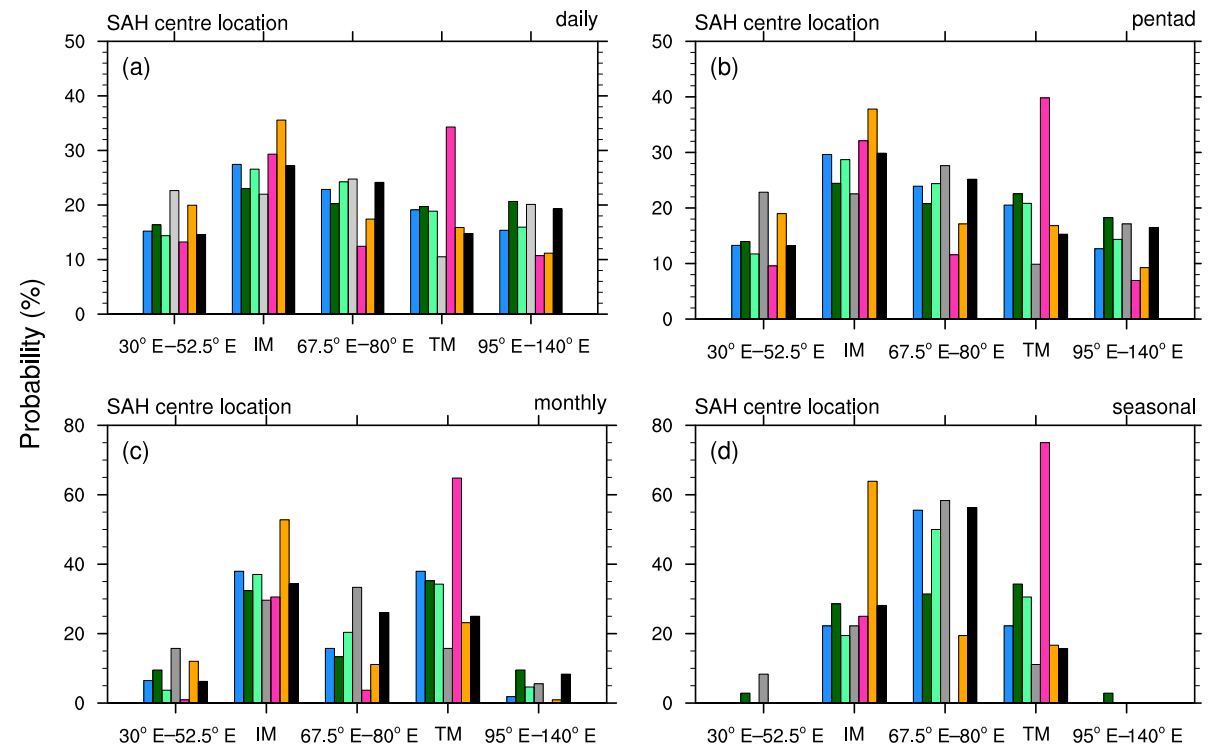

Longitude
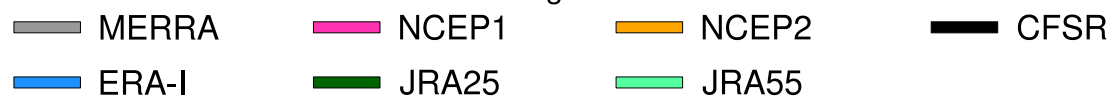

Figure 2. Overview of the probability distributions of the SAH's longitudinal location at $100 \mathrm{hPa}$ based on (a) daily, (b) pentad, (c) monthly and (d) seasonal data during June to August 1979-2014 (1979-2010 for CFSR and 1979-2013 for JRA-25). The IM and TM regions comprise the longitudes $55-65$ and $82.5-92.5^{\circ}$ E respectively.

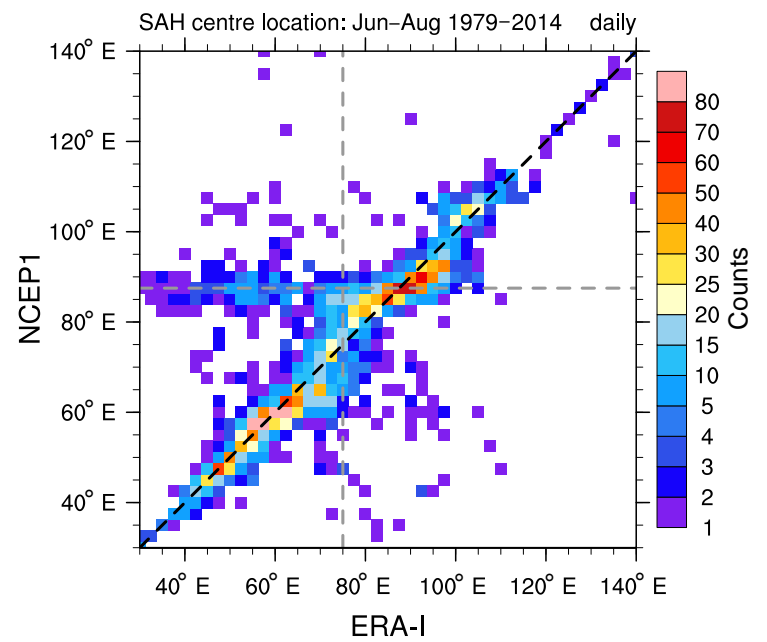

Figure 3. Scatter plot of the daily longitudinal location of the SAH centre during June-August 1979-2014 at $100 \mathrm{hPa}$ as diagnosed by ERA-I and NCEP-1 (note the non-linear colour scale). Dashed black line indicates the perfect one-to-one correspondence and grey lines indicate strong deviations from the perfect fit.

\subsubsection{SAH location based on daily mean data}

Figure 5 shows the location of the SAH based on daily JJA data for the period 1979-2014 (1979-2010 for CFSR and 1979-2013 for JRA-25) for these seven reanalyses. Obviously, only NCEP-1 shows a clear double-peak structure.
Note that NCEP-2, which has the same native resolution as NCEP-1 but includes updated physics and corrections of errors (Kanamitsu et al., 2002), shows a smoothed out TM. Nevertheless, NCEP-2 is the reanalysis that agrees the best with NCEP-1 in terms of producing two modes. As an example, only NCEP-1 and NCEP-2 show a sharp peak over the IP. The reanalyses that show the best agreement are CFSR, ERA-I and JRA-55. These reanalyses have a high horizontal model resolution $\left(<1^{\circ}\right)$ and ERA-I and JRA-55 use 4DVar data assimilation (see Table 1). Although MERRA - also a high-resolution reanalysis - does not agree in detail with CFSR, ERA-I and JRA-55, the following points are supported by all four of these reanalyses: the IP seems at least as important as the TP, the SAH is almost as likely located in the region $70-80^{\circ} \mathrm{E}$ as in any other region of the broad centre region ( $\sim 50-100^{\circ} \mathrm{E}$, depending on the reanalysis), the peak over the TP is shifted farther eastward than in the NCEP-1 data. We have found similar results for the analysis based on pentad mean data (see Fig. 2b).

When comparing the distributions of the daily location of the SAH centre for individual years, we have found strong interannual variability (not shown). Despite this interannual variability, peaks in the distribution of individual years, as diagnosed by NCEP-1 and NCEP-2, are usually consistent with the multi-annual mean displayed in Fig. 5. In contrast, the other reanalyses exhibit more variability, e.g. there are years that show a clear preference of the eastern or western 

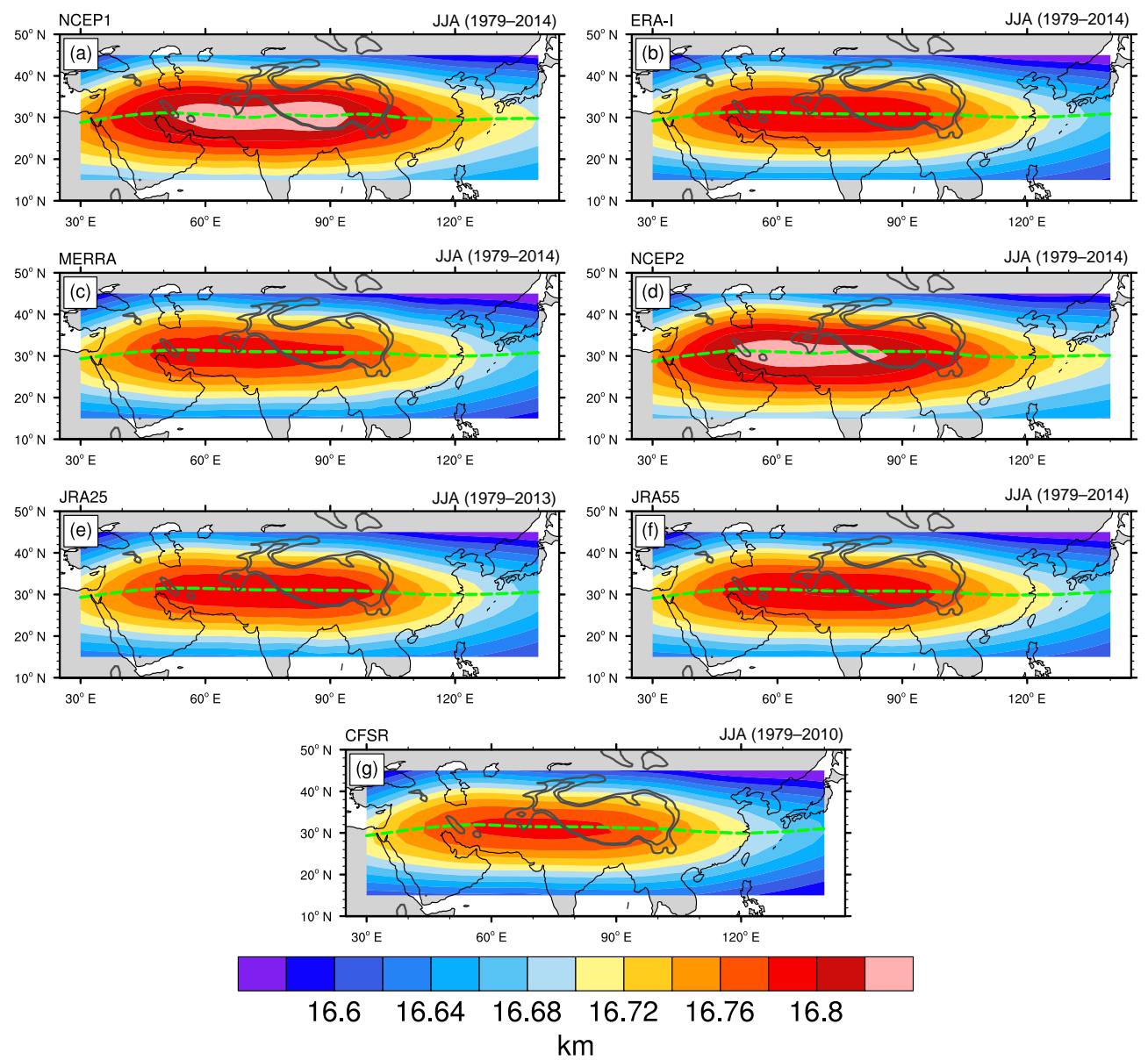

Figure 4. Climatology of geopotential height $(\mathrm{km})$ at $100 \mathrm{hPa}$ for the seven reanalyses during JJA 1979-2014. For JRA-25 and CFSR the periods of 1979-2013 and 1979-2010 are considered. Green lines indicate the climatological ridgelines from the data sets. Black contours display the orography of 2 and $3 \mathrm{~km}$ for orientation.

side and some years also exhibit two centres of activity, however with varying geographical position.

\subsubsection{SAH location based on monthly mean data}

Figure 6 shows the PDF of the SAH centre location based on the diagnosis of monthly mean data for JJA 1979-2014 (1979-2010 for CFSR and 1979-2013 for JRA-25). The distribution has been smoothed by taking the running average over three grid points. We include this step because for monthly (seasonal) mean data only 108 (36) data points for the years 1979 to 2014, in combination with the bin size of $2.5^{\circ}$, result in a low ratio of data points per bin and thus artificial peaks, which should not be overinterpreted. Moreover, sometimes the location of the maximum in geopotential is not unique, i.e. two or more neighbouring boxes have the same geopotential value.

For the monthly mean data all reanalyses show a bimodal structure with one local maximum close to $60^{\circ} \mathrm{E}$ and a second maximum close to $85^{\circ} \mathrm{E}\left(90^{\circ} \mathrm{E}\right.$ for CFSR and $75^{\circ} \mathrm{E}$ for MERRA). The best agreement can be found between JRA-
55 and ERA-I. Analysing the months June, July and August separately shows that in JRA-55 and ERA-I this structure is due to the distributions during June and July. In both months a double-peak structure with a notably stronger (weaker) TM (IM) in June than in July can be observed, whereas in August the distribution is rather smooth for JRA-55 and ERA-I (not shown). For each of the months June, July and August, the distribution of the SAH centre based on NCEP-1 (NCEP-2) shows the typical bimodal structure with a more pronounced TM (IM) than IM (TM). Common to all reanalyses is that there is a shift of the distribution to the west from June to July and a shift back to the east from July to August.

\subsubsection{SAH location based on seasonal mean data}

Based on seasonal mean (JJA mean) data the SAH shows a bimodal structure in the reanalyses NCEP-1 and NCEP-2 (see Fig. 7). Here, NCEP-1 shows a pronounced peak over the TP and a second one over the IP, whereas NCEP-2 shows only a sharp peak over the IP. Additionally, JRA-25 shows low probabilities around $70^{\circ} \mathrm{E}$. In contrast, CFSR, ERA-I, 


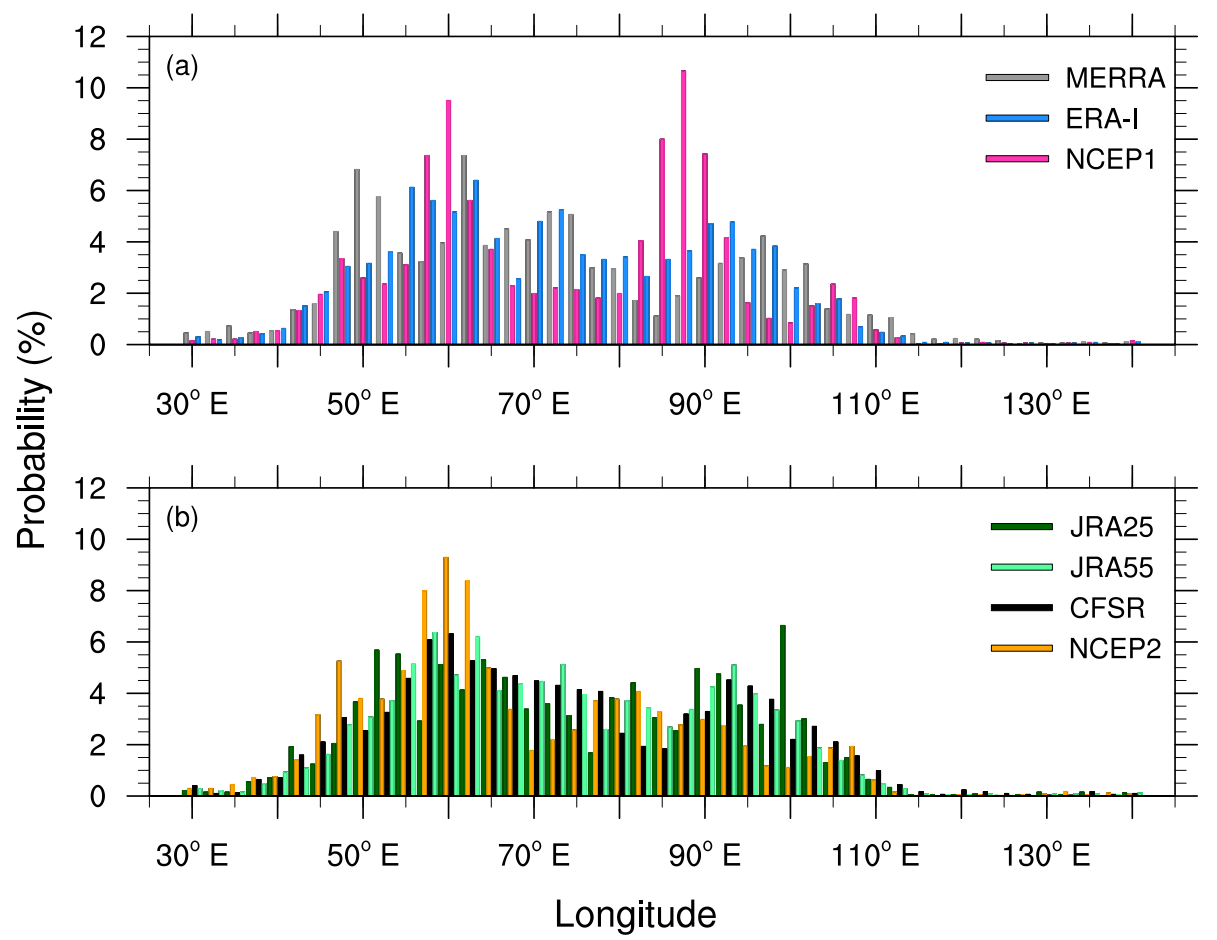

Figure 5. PDF of the daily location of the SAH centre at $100 \mathrm{hPa}$ during JJA 1979-2014 (1979-2010 and 1979-2013 for CFSR and JRA-25) for the seven reanalyses. The binning was performed according to the $2.5^{\circ}$ resolution of the data.

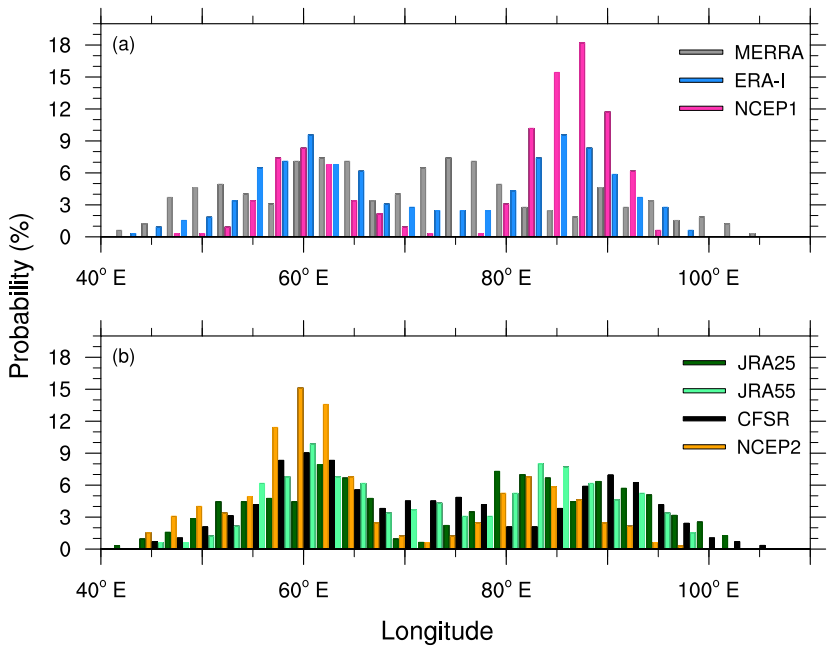

Figure 6. As Fig. 5 but for monthly mean data. Additionally the original distribution has been smoothed using a running average over three grid points $\left(7.5^{\circ}\right)$.

JRA-55 and MERRA show high probabilities over the whole centre region $\left(\sim 60-85^{\circ} \mathrm{E}\right.$, depending on the reanalysis).

Our analysis of the SAH centre location at $100 \mathrm{hPa}$ indicates that based on daily, pentad and seasonal data only NCEP-1 shows a clear bimodal structure. We emphasise that in particular the results based on daily and pentad data are of interest as they should be linked to the synoptic movement of

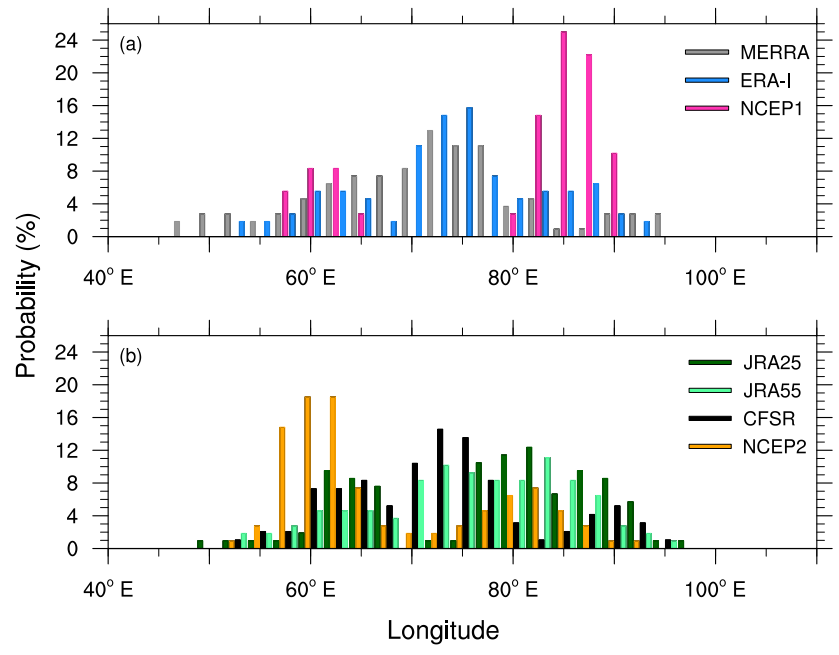

Figure 7. As Fig. 6 but for seasonal mean (JJA) data.

the SAH. Based on monthly mean data all reanalyses show higher probabilities of occurrence over the TP and IP. The occurrence of the SAH centre based on daily, pentad, monthly and seasonal mean data is summarised in Fig. 2. Different probability distributions of the SAH with respect to daily, pentad, monthly and seasonal mean data arise as there is no weighting of the strength of the SAH centre with respect to its surroundings. This issue is addressed with a more visual 
explanation in the next section. We also note that the quantitative results are likely to depend on the height level and time period chosen.

The salient disagreement of the reanalyses in the distribution of the SAH centre location is our motivation to revisit the questions of how the SAH moves on various timescales and how this movement is caused. To tackle these questions, we will focus on results based on observational and ERA-I data during the next two sections (Sects. 4 and 5). We choose ERA-I as it is a heavily used reanalysis with the most recent data assimilation scheme. Apart from that, our choice is arbitrary and we address the sensitivity of the presented results with respect to the reanalysis in the discussion (Sect. 6).

\section{Movement and drivers of the SAH}

Simple model studies have shown that constant diabatic heating in South Asia causes a mean UTLS circulation to its north-west, which resembles the climatological SAH (see Gill, 1980; Hoskins and Rodwell, 1995). As diabatic heating in the southern monsoon region is largely caused by the latent heat release due to convection, we use OLR as a proxy for convective activity and consequently for diabatic heating.

Figure 8 shows the temporal evolution of ERA-I geopotential (averaged over $20-40^{\circ} \mathrm{N}$ ) during the summer months of 1983 and 1987. Choosing these two years is arbitrary; however, they are useful in illustrating common and individual features of the monsoon season. The green lines indicate the location of the SAH centre as diagnosed via the method described in Sect. 2.2 based on daily (light green) and pentad (dark green) data from ERA-I. Additionally, we have included mean OLR in the region $15-30^{\circ} \mathrm{N}$ (main convective region south of the $\mathrm{SAH}$ ) from NOAA at the levels 190 and $180 \mathrm{~W} \mathrm{~m}^{-2}$ (black contours).

In Fig. 8 the lowest OLR values are mostly confined to the area $75-105^{\circ} \mathrm{E}$ and are mostly located east of the highest geopotential height values. East of the OLR minimum we can observe eastward migration of high geopotential, associated with eastward eddy shedding of the anticyclone. A strong shedding event is observed in mid-region August 1983 (turquoise star in Fig. 8a). West of the OLR minimum region, the core of the anticyclone usually propagates westward. Another feature that is visible in the Hovmöller diagrams is the splitting of the anticyclone, e.g. $\sim 10$ July 1983, $\sim 10$ July 1987 and the end of July 1987 (indicated by arrows in Fig. 8). Splitting events and the development of high geopotential values close to the OLR forcing are often a cause for "jumps" of the location of the SAH centre (dark green line in Fig. 8).

Figure 9 shows geopotential height along the ridgeline during June to August 1983 for individual pentads, monthly mean and seasonal mean data. We note that in 1983, based on daily means, all reanalyses show a distribution of the $\mathrm{SAH}$ centre that has one strong centre at approximately $60^{\circ} \mathrm{E}$ and a weaker maximum at approximately $95^{\circ} \mathrm{E}$ (not shown). The

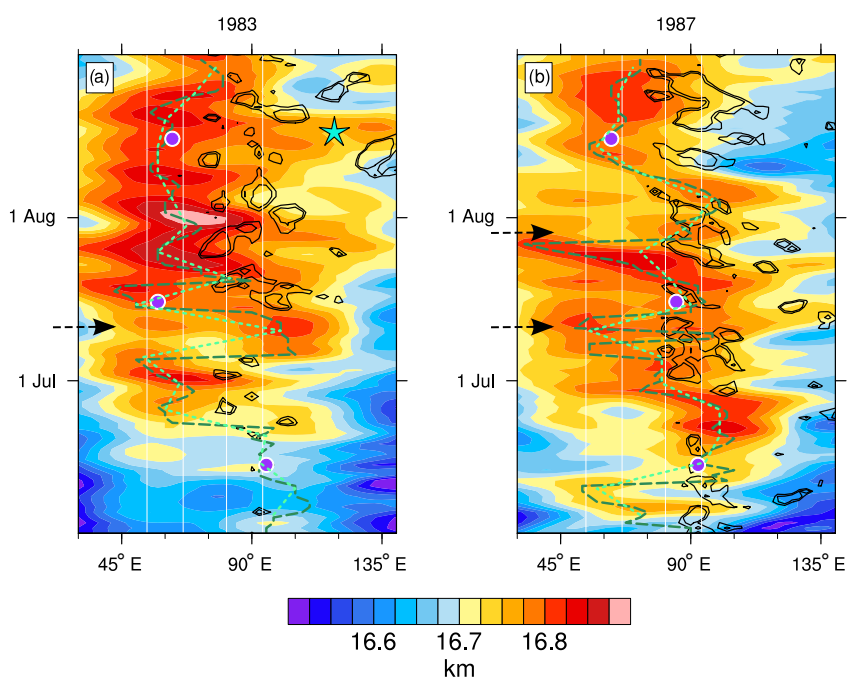

Figure 8. Hovmöller plots of geopotential height at $100 \mathrm{hPa}$ (averaged over 20-40 ${ }^{\circ} \mathrm{N}$ ) in km from ERA-I in summer (JJA) (a) 1983 and (b) 1987. Black contours show OLR (averaged over 15$30^{\circ} \mathrm{N}$ ) from NOAA at levels of $180 \mathrm{~W} \mathrm{~m}^{-2}$ (inner contours) and $190 \mathrm{~W} \mathrm{~m}^{-2}$. Dashed dark green and light green show the movement of the SAH centre based on daily and pentad data. Purple dots show the location of the SAH based on monthly data. White lines indicate the IM (left) and TM (right) region. Arrows indicate splitting events discussed in the text. Turquoise star shows the strong shedding event in August 1983.

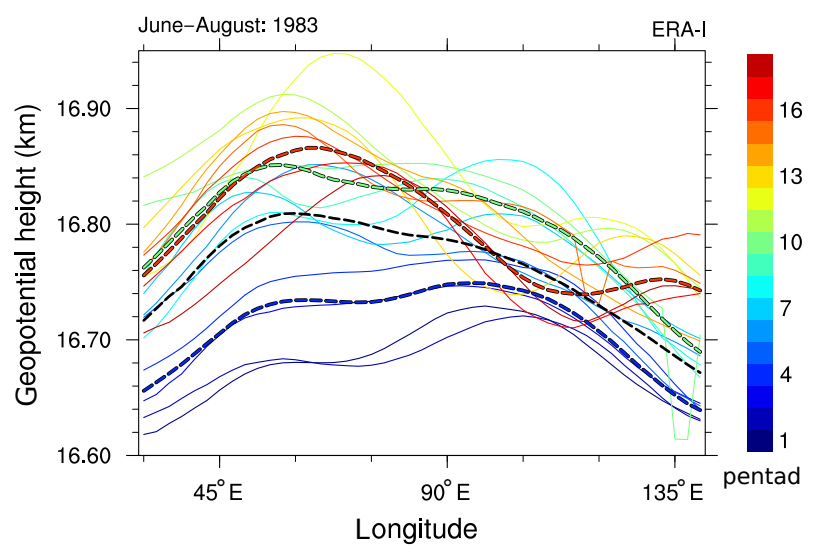

Figure 9. Geopotential height $(\mathrm{km})$ along the ridgeline of the $\mathrm{SAH}$ for individual pentads (colour-coded solid lines) in 1983. The first pentad is 3-7 June 1983. Dashed lines show geopotential height along the ridgeline based on June (blue), July (green), August (red) and the seasonal (JJA) mean data (black) in 1983.

SAH centre is located over the TP in June and over the IP in July and August (coloured dashed lines in Fig. 9 and purple dots in Fig. 8a). The seasonal mean shows a maximum over the IP (dashed black line in Fig. 9). The effect, which leads to different distributions with respect to varying timescales, can be inferred from the ridgelines for the months June and August in Fig. 9: during June the maximum in the TP is 


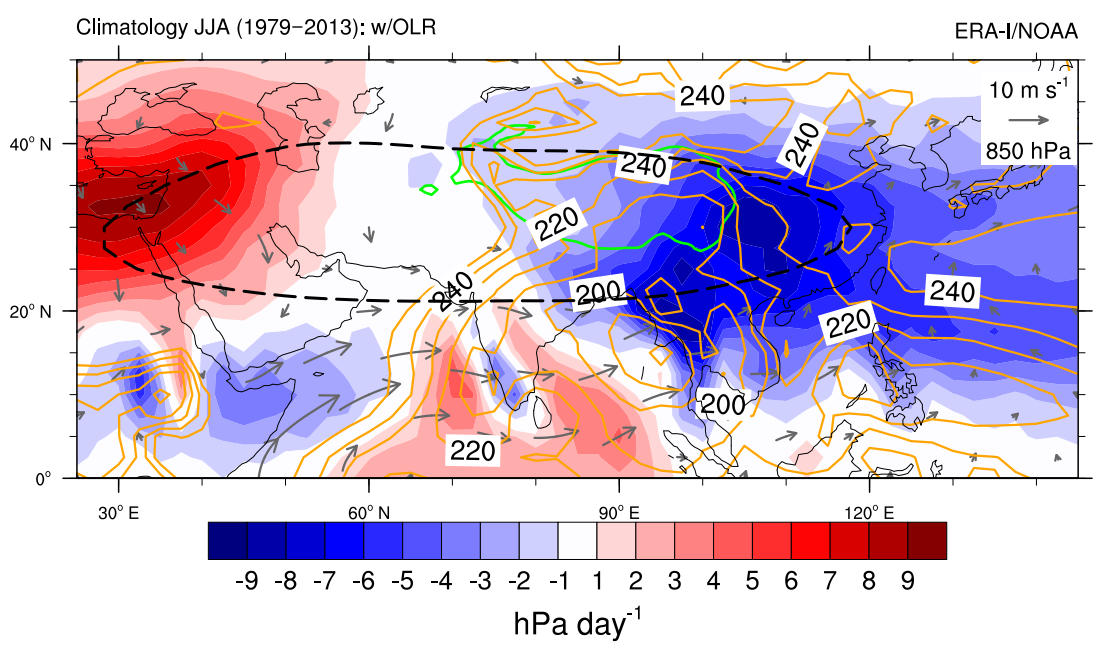

Figure 10. Mean vertical velocity (hPa day ${ }^{-1}$ ) at $100 \mathrm{hPa}$ during JJA (1979-2013) as diagnosed from ERA-I. Upward (downward) winds are indicated by blue (red) colours. Orange contours show mean OLR $\left(\mathrm{W} \mathrm{m}^{-2}\right)$ starting from 250 to $180 \mathrm{~W} \mathrm{~m}^{-2}$ in steps of $10 \mathrm{~W} \mathrm{~m}^{-2}$ during the same period. Black dashed contour indicates the climatological mean position of the SAH (16.72 km contour of geopotential height at $100 \mathrm{hPa}$ ). Arrows show the mean JJA (1979-2013) $850 \mathrm{hPa}$ horizontal winds from ERA-I. Green contour indicates the $3 \mathrm{~km}$ contour of the Tibetan Plateau.

weak, whereas during August the maximum over the IP is pronounced. Nevertheless, both months contribute equally to the distribution of the SAH based on monthly mean data, whereas based on seasonal mean data, the peak will be detected over the IP only.

In 1987 the east mode is found based on seasonal data and a rather smoothed out distribution is found based on the daily analysis.

To illustrate the climatological connection between OLR and the SAH, we display the JJA climatology (1979-2013, i.e. the overlapping time period of NOAA OLR and ERA-I data) of the SAH location at $100 \mathrm{hPa}$ (dashed black line) and of OLR (orange contours) in Fig. 10. Additionally, we show the climatology of vertical velocities at $100 \mathrm{hPa}$ as diagnosed from ERA-I (colour shading) and the low level winds (grey vectors), e.g. identifying the Somali Jet, which brings moisture from the Arabian Sea to India (Rodwell and Hoskins, 1995).

The deep convective region is located to the south-east of the climatological location of the SAH (dashed black contour in Fig. 10), with the lowest OLR values (below 180$190 \mathrm{~W} \mathrm{~m}^{-2}$ ) over the Bay of Bengal. Upward (downward) winds are located on the eastern (western) side of the SAH in agreement with Rodwell and Hoskins (1996).

The mean seasonal evolution of the SAH location and strength together with OLR during May-September (19792013) is shown in Figs. 11a and 12. Until approximately mid-July the area of strong convective activity extends northwestward and retreats south-eastward later. In a similar way the location of the SAH moves north-westward during the build up of the SAH and south-eastward during the decay phase of the SAH (shifting $\sim 30^{\circ}$ longitudinally and $\sim 10$ $15^{\circ}$ latitudinally). The seasonal east-west shift can also be found in daily precipitation data from GPCP during the period 1997-2013 (see Fig. 11b), and the seasonal northward migration of precipitation has been noted in previous studies (e.g. Yihui and Chan, 2005, their Fig. 3). We note that in contrast to the expansion of low OLR and high precipitation values, the region of lowest OLR and highest precipitation $\left(\sim 90^{\circ} \mathrm{E}\right)$ in Fig. 11 does not shift notably.

To further study the relation of convection (OLR) to the SAH we investigate the temporal correlation of NOAA OLR with geopotential at $100 \mathrm{hPa}$ from ERA-I on subseasonal timescales. Therefore, we calculate time lag correlations of OLR averaged over the region $70-130^{\circ} \mathrm{E} \times 15-30^{\circ} \mathrm{N}$ (i.e. the deep convective region on the south-eastern border of the $\mathrm{SAH}$ ) with geopotential averaged over $20-40^{\circ} \mathrm{N}$. Before calculating the correlations based on data from May to September 1979-2013, the data were deseasonalised and oscillations with a period of less than 10 days were removed. The results of the time lag analysis are shown in Fig. 13. At around time lag zero the maximum anticorrelation $(<-0.50)$ is found at approximately $75-85^{\circ} \mathrm{E}$ and moves westward with increasing time lag. Approximately 3 days later the maximum anticorrelation $(<-0.45)$ is found around $45^{\circ} \mathrm{E}$. East of the instantaneous response region the maximum anticorrelation travels eastward more slowly, e.g. the maximum anticorrelation at a time lag of 4 days $(<-0.35)$ can be found at approximately $90-95^{\circ} \mathrm{E}$.

The north-west to south-east movement found in the seasonal cycle of the SAH can also be identified on the interannual timescale. Table 3 shows the correlation of longitude and latitude occurrence of the SAH centre for the seven reanalysis data sets. The correlation coefficients are calculated 

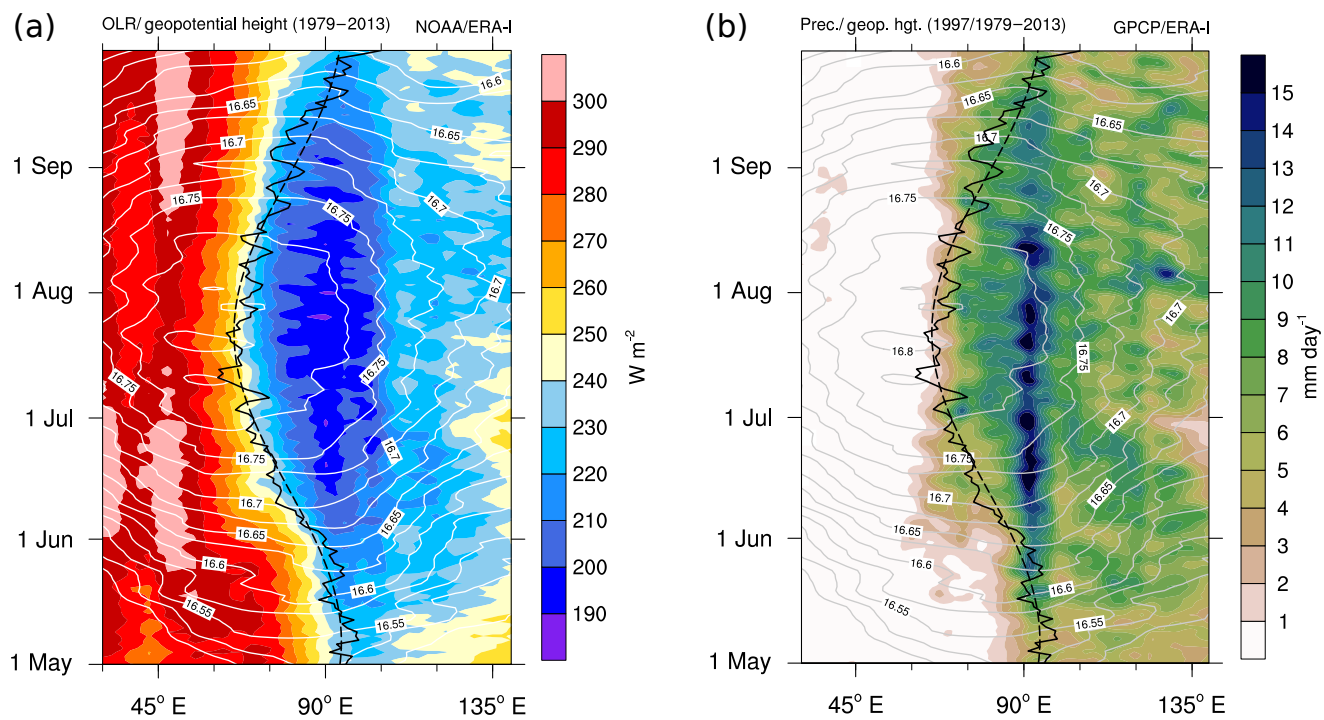

Figure 11. (a) Hovmöller diagram (longitude vs. time) of OLR (NOAA, $15-30^{\circ} \mathrm{N}$ average in $\mathrm{W} \mathrm{m}^{-2}$ ) and geopotential height (km) at $100 \mathrm{hPa}$ (ERA-I, 20-40 $\mathrm{N}$ average, white contours) averaged over the years 1979-2013. The black solid line indicates mean location of the SAH centre during the same period. The dashed line represents the low-pass-filtered mean location of the SAH, i.e. periods less than 80 days are removed from the black solid line. (b) As in panel (a) but colour coded is GPCP daily precipitation $\left(\mathrm{mm} \mathrm{day}^{-1}\right)$ at $1 \times 1^{\circ}$ resolution averaged over $15-30^{\circ} \mathrm{N}$ during the years $1997-2013$. Precipitation data has been smoothed by $3^{\circ}$ longitudinally and 3 days temporally.

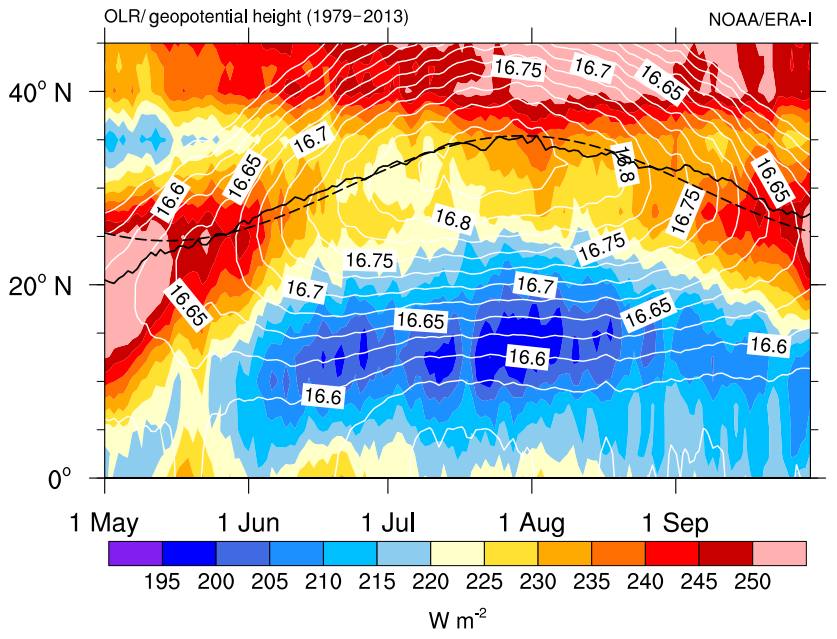

Figure 12. As Fig. 11 but for latitude vs. time. OLR and geopotential height $(\mathrm{km})$ at $100 \mathrm{hPa}$ have been averaged over $70-130$ and $45-100^{\circ}$ E respectively.

based on the seasonal mean and monthly mean data during 1979-2014 (1979-2010 for CFSR and 1979-2013 for JRA$25)$. For the latter the multiannual mean of each month has been subtracted in order to deseasonalise the data (in the following this will be referred to as deseasonalised monthly mean data).

For seasonal mean and deseasonalised monthly mean data all reanalyses show that westward (eastward) movement of the SAH is related to northward (southward) movement. The

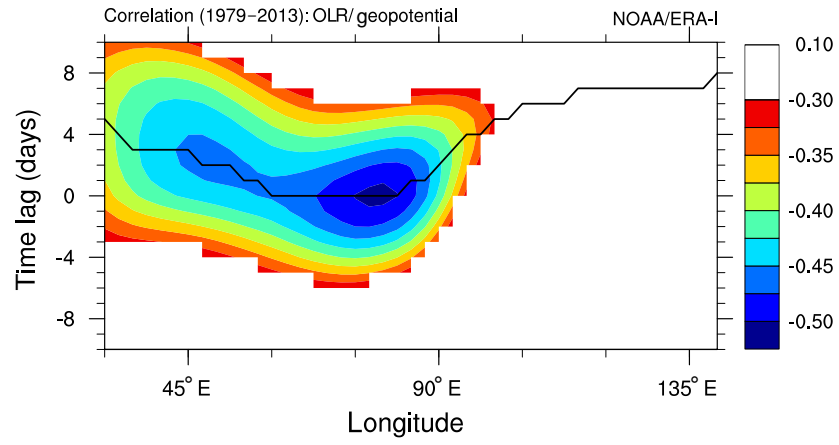

Figure 13. Correlation between NOAA OLR (averaged over 15$30^{\circ} \mathrm{N} \times 70-130^{\circ} \mathrm{E}$ ) and ERA-I geopotential (averaged over 20 $40^{\circ} \mathrm{N}$ ) at $100 \mathrm{hPa}$ depending on time lag and longitude. Positive lags indicate that geopotential changes occur after OLR changes. Correlation is calculated based on the deseasonalised and smoothed (periods shorter than 10 days removed) time series from May to September for every year separately and then averaged over the 35 year period 1979-2013 (period covered by OLR and geopotential data). The black line shows the maximum anticorrelation at each longitude.

separate analysis of June, July and August yields that this relationship is strong during June and July (significant on the $10 \%$ level in all reanalyses). In August, however, the connection is weaker and becomes insignificant for most reanalyses (on the $10 \%$ significance level, weakest anticorrelation of -0.08 found in MERRA data). 
Table 3. Correlation of longitudinal and latitudinal location of the SAH centre based on seasonal mean (JJA mean) and monthly mean (deseasonalised) data from June to August 1979-2014 (1979-2010 for CFSR and 1979-2013 for JRA-25). Asterisks indicate the significance levels of the correlation coefficients.

\begin{tabular}{lrr}
\hline & Seasonal mean & Monthly mean \\
\hline CFSR & $-0.41^{* *}$ & $-0.37^{*}$ \\
ERA-I & -0.28 & $-0.29^{*}$ \\
JRA-25 & $-0.53^{*}$ & $-0.53^{*}$ \\
JRA-55 & $-0.36^{* *}$ & $-0.35^{*}$ \\
MERRA & $-0.48^{*}$ & $-0.26^{*}$ \\
NCEP-1 & -0.15 & -0.15 \\
NCEP-2 & -0.22 & $-0.35^{*}$ \\
\hline
\end{tabular}

Significance level: ${ }^{* *}(0.05),{ }^{*}(0.01)$.

In summary, we have found that the SAH's location and strength are notably related to the location and strength of convection located on its south-eastern border (on climatological, seasonal and subseasonal timescales). This connection is especially prominent in the mean seasonal evolution. Moreover, the seasonal north-west to south-east movement of the $\mathrm{SAH}$ is also evident in the seasonal mean and in the deseasonalised monthly mean data in summer, leading to the hypothesis that changes in the location of convection are related to the movement of the $\mathrm{SAH}$ on these timescales as well. This hypothesis will be tested via composite analyses in the next section (Sect. 5).

\section{Composite analyses of western and eastern phases}

Regardless of the existence of two preferred spatial modes of the SAH, it is of great interest to identify signatures that are associated with an eastward or westward location of the SAH centre. The days, months, summers and years with a rather (see exact definition later) westward (eastward) location of the SAH centre will be termed western (eastern) days, months and summers.

A similar method has been applied by Yan et al. (2011), who analysed satellite measurements (of $\mathrm{O}_{3}, \mathrm{H}_{2} \mathrm{O}$ and $\mathrm{CO}$ ) with respect to the location of the $\mathrm{SAH}$ as diagnosed by NCEP-1 daily data. These composites show a dipole pattern in the distribution of trace gas anomalies where positive (negative) values of tropospheric (stratospheric) tracers are collocated with the current location of the SAH. This illustrates how trace gas anomalies follow the movement of the SAH (see also Randel and Park, 2006; Garny and Randel, 2013).

The importance of the location of the SAH centre can be inferred from Fig. 14, which displays geopotential height composites (grey contours) at $100 \mathrm{hPa}$ together with anomalies of the vertical velocities at $100 \mathrm{hPa}$ for west (Fig. 14a) and east (Fig. 14b) summers during 1979-2013. A year belongs to the west (east) composite if the seasonal (JJA) SAH centre is located more than $7.5^{\circ}$ to the west (east) of the multiannual mean location of the SAH centre (resulting in eight summers for each composite). During western years the SAH tends to be slightly stronger and negative anomalies in the vertical velocities (i.e. relative upward transport of the order of $25 \%$ of the maximum climatological values; see Fig. 10) in the centre region are found. This could be an indicator of stronger confinement and enhanced upward transport during western summers. For the eastern summers, the anomalies are exactly reversed, i.e. regions of anomalous upward motion during western years show anomalous downward motion during eastern years and vice versa.

To identify the signatures associated with the longitudinal location of the $\mathrm{SAH}$, we will use composite differences of OLR (NOAA) and precipitation (GPCP). In detail, the respective data are split according to the location of the SAH centre in ERA-I data into western and eastern composites. Finally, the two composites are subtracted from each other (we show results as west minus east).

We will present analyses based on seasonal mean, monthly mean and daily data from June to August. To separate the effect of the seasonal cycle (see Figs. 11 and 12) from subseasonal processes within the monthly mean and daily data, we use the deseasonalised monthly and daily means of OLR, precipitation and surface temperature (for daily data the June to August period of the smoothed seasonal cycle based on May to September data from 1979 to 2013 was removed). Accordingly, the split into eastern and western phases is done with respect to $\pm 7.5^{\circ}$ deviation from the multiannual summer mean, from the multiannual monthly means or from the smoothed seasonal cycle (see dashed line in Fig. 11) of the longitudinal position of the SAH centre.

The following results are also supported (qualitatively) if we split according to $\pm 1 \sigma$, where $\sigma$ represents the multiannual seasonal, multiannual monthly or multiannual daily standard deviation. Similarly, splitting the data into western $\left(<67.5^{\circ} \mathrm{E}\right)$ and eastern $\left(>80^{\circ} \mathrm{E}\right)$ phase or location over the IP and TP leads to comparable results. This might be due to the fact that subseasonal variations dominate the seasonal variations. For the seasonal data the three methods give almost the same composites (see Fig. 2d, mean location of $73.5^{\circ}$ and standard deviation of $\sim 9^{\circ}$ ) and hence similar results.

Figure 15 shows composite differences of OLR and precipitation with respect to different timescales (for daily data there is no precipitation composite because daily resolved GPCP data are only available from October 1996 onward). For seasonal, monthly and daily data the western (eastern) composite is comprised of 8,39 and $1222(8,38,1087)$ data points respectively. Areas that do not reach the $10 \%$ significance level are dotted.

Two main regions that show significant differences between western and eastern phases in OLR and in precipitation are India and the western Pacific. In detail, OLR is lower (higher) during western (eastern) periods over India 

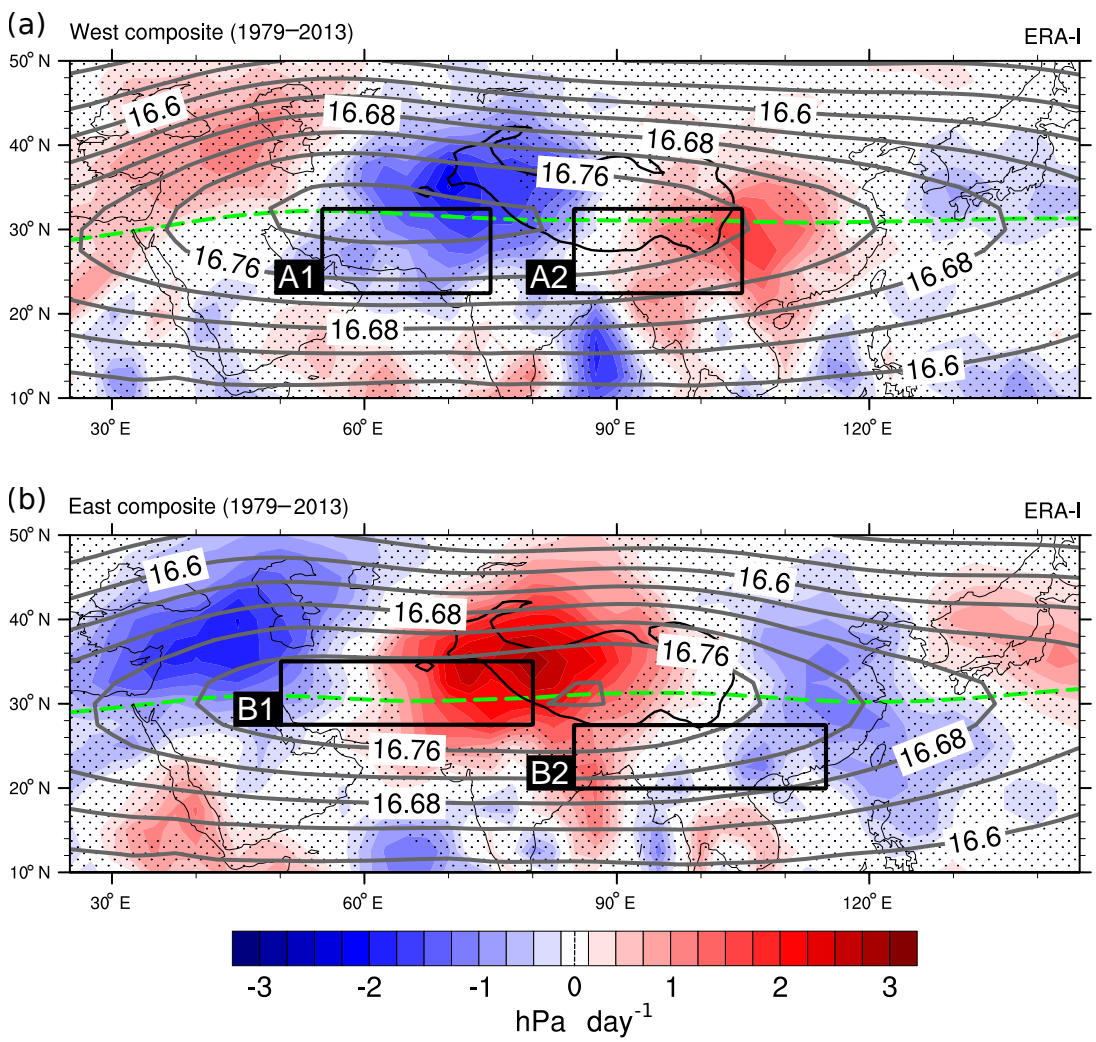

Figure 14. Colour shading displays the mean anomaly of the vertical velocity $\left(\mathrm{hPa} \mathrm{day}^{-1}\right.$ ) at $100 \mathrm{hPa}$ from ERA-I during (a) west and (b) east summers with respect to the JJA mean during 1979-2013. Stippling indicates where the anomalies are insignificant (significance less than $10 \%$ ). Grey contours show composites of ERA-I geopotential height at 100hPa (in km) during (a) western and (b) eastern summers. The green lines indicate the ridgelines. Black contour shows orography greater than $3 \mathrm{~km}$. Black boxes show the averaging regions of geopotential, needed to calculate the $\mathrm{SAHI}_{14}$ and the $\mathrm{SAHI}_{15}$. The $\mathrm{SAHI}_{14}$ and $\mathrm{SAHI}_{15}$ are defined as the standardised differences of average geopotential in box A2 $\left(22.5-32.5^{\circ} \mathrm{N}, 85-105^{\circ} \mathrm{E}\right)$ minus $\mathrm{A} 1\left(22.5-32.5^{\circ} \mathrm{N}, 55-75^{\circ} \mathrm{E}\right)$ and in box B2 $\left(20-27.5^{\circ} \mathrm{N}, 85-115^{\circ} \mathrm{E}\right) \mathrm{minus} \mathrm{B} 1\left(27.5-35^{\circ} \mathrm{N}\right.$, $\left.50-80^{\circ} \mathrm{E}\right)$ respectively.

and the Arabian Sea. For the western Pacific the reverse connection is found. Furthermore, the results from precipitation data are in agreement with the results from OLR data, i.e. lower (higher) OLR values are accompanied by more (less) rainfall. Additionally, there is less OLR in the deep tropics, indicating more convective rainfall in this region during western phases. This is most pronounced in the monthly data (Fig. 15c and d). In comparison with seasonal and monthly mean data (Fig. 15a and c) there is an important difference for the daily data (Fig. 15e) because negative OLR values stretch farther from west to east at approximately $20-30^{\circ} \mathrm{N}$.

The analysis for June, July and August separately (not shown) shows that in June and July, the significant differences are mostly in agreement with the results found for the monthly JJA data. In August, however, almost no significant differences of precipitation can be found over India.

In short, we have found that the western-eastern location of the SAH is connected to opposing anomalies of convection and precipitation over India and over the western Pacific with respect to daily, monthly and seasonal data. Stronger (weaker) precipitation over India (the western Pacific) is related to a more westward location of the SAH centre.

\section{Discussion}

The comparison of the daily location of the SAH centre during JJA 1979-2014 as diagnosed from NCEP-1 and ERA-I shows that NCEP-1 exhibits strong bimodality in its longitudinal location (in agreement with Zhang et al., 2002; Yan et al., 2011), whereas ERA-I shows only a pronounced signature over the IP. This difference is also visible in the longterm climatology, i.e. there is bimodality in the NCEP-1 climatology of geopotential at $100 \mathrm{hPa}$.

In the analysis of seven reanalysis data sets (CFSR, ERA-I, JRA-25, JRA-55, MERRA, NCEP-1, NCEP-2) with respect to the location of the SAH we find that only NCEP-1 produces a pronounced maximum over the TP and a distinct minimum in the region $67.5-80^{\circ} \mathrm{E}$, i.e. between the IP and the TP. Furthermore, only NCEP-1 and NCEP- 2 show a sharp peak over the IP. 


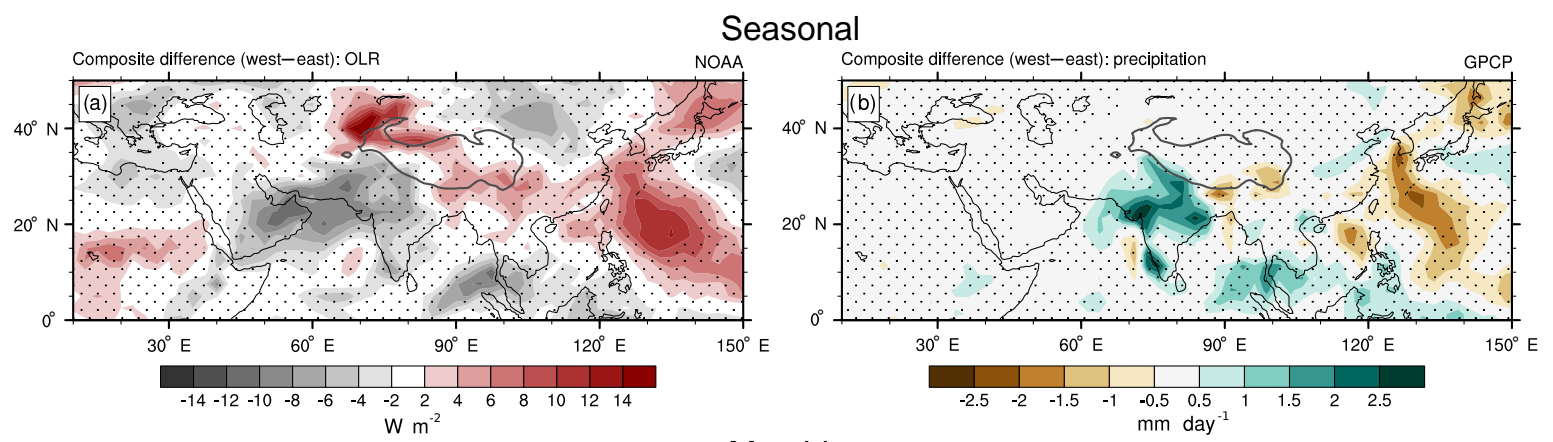

Monthly
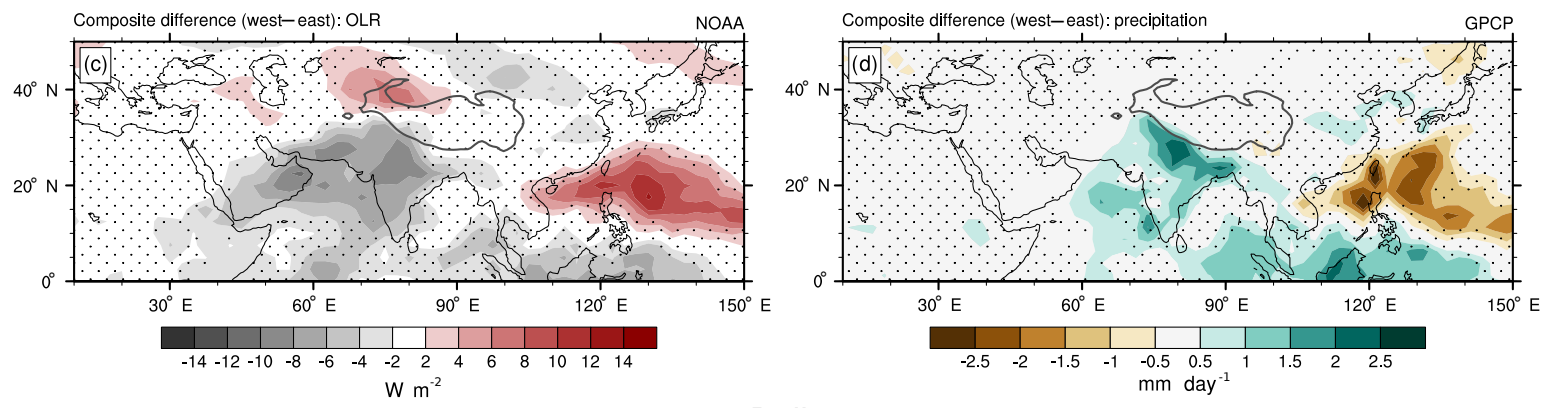

Daily

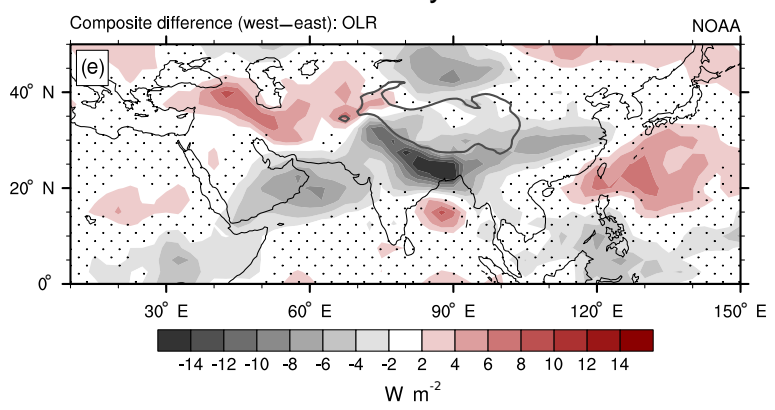

Figure 15. Composite differences of west minus east location of the SAH centre in the period 1979-2013 as diagnosed by ERA-I for (a, c, e) OLR (from NOAA in $\mathrm{W} \mathrm{m}^{-2}$ ) and (b, d) precipitation (from GPCP in mm day ${ }^{-1}$ ) based on (a, b) seasonal, (c, d) monthly and (e) daily data. Stippling indicates insignificant areas (significance less than $10 \%$ ). Black contours show the location of the TP (orography higher than $3 \mathrm{~km})$.

Although there are differences between all reanalyses, NCEP-2 and especially NCEP-1 are outliers regarding the distribution of the $\mathrm{SAH}$ centre at $100 \mathrm{hPa}$. The reanalysis data sets that show the best agreement regarding the location of the SAH centre are CFSR, ERA-I and JRA-55.

The analysis of individual years shows strong interannual variability in the location of the SAH. This variability limits the application of the findings for the long-term mean to single years and vice versa. For example, the distribution of low PV at $380 \mathrm{~K}$ in 2006 as shown in Garny and Randel (2013) (see their Fig. 15), which is based on MERRA data, exhibits high values on the western side $\left(\sim 30-70^{\circ} \mathrm{E}\right)$. This is in good agreement with the distribution of the SAH centre location at $100 \mathrm{hPa}$ in 2006, which is rather shifted to the west in all reanalyses, except for NCEP-1 (not shown).

Based on monthly mean data over the period JJA 19792014 (1979-2010 for CFSR and 1979-2013 for JRA-25) we have found that all reanalyses (except for MERRA) show two regions of increased probability, which lie over the IP and TP (see Fig. 2c). However, as for the daily data, based on the monthly data NCEP-1 (NCEP-2) shows a more pronounced TM (IM) than ERA-I, JRA-55 and JRA-25. After analysing the months June, July and August separately we have found that in the latter three reanalyses two centres of activity can be found in June and July (weaker IM in June and stronger IM in July), whereas in August the distribution is rather smooth for ERA-I and JRA-55 (not shown).

Based on seasonal data we can identify bimodality in NCEP-1 and NCEP-2. As before, NCEP-1 (NCEP-2) shows a strong TM (IM) and a weaker IM (TM). Additionally, JRA25 shows low occurrences of the SAH in the region between the IP and TP. CFSR, ERA-I, JRA-55 and MERRA show a spread-out distribution over the region $55-90^{\circ} \mathrm{E}$ with a single peak at $\sim 70-80^{\circ} \mathrm{E}$, depending on the reanalysis. 
Possible reasons for the different distributions as given by the reanalyses with respect to varying timescales (except for NCEP-1 and NCEP-2, which show consistent distributions on all timescales) are as follows: (1) the method of locating the SAH centre picks the highest local maximum for individual samples and does not take the relative strength of the current SAH centre into account. (2) It is rather unlikely that the $\mathrm{SAH}$ centre is located west of $55^{\circ} \mathrm{E}$ or east of $92.5^{\circ} \mathrm{E}$ for many subsequent days, hence there is almost no occurrence of the $\mathrm{SAH}$ in this region based on monthly means. However, on a daily and pentad basis locations to the west of the IP and to the east of the TP have a significant weight (see Fig. 2), thus putting weight to the IM or TM on a monthly basis when the SAH resides rather to the west or east. (3) The bimodality in the monthly data might be influenced by the seasonal cycle.

The reasons for the differences in the SAH centre location between the reanalyses are attributable to the underlying model, the assimilation technique and the observational data, which are assimilated by the different reanalyses. While it is not possible for us to disentangle the relative influence of these sources, some hints might be as follows: numerous changes have been made from NCEP-1 to NCEP-2. These changes affect the thermal and orographic forcing of the IP and TP as well as the diabatic heating associated with tropical convection, e.g. through changed boundary conditions, updated physics and smoothed orography (Kanamitsu et al., 2002). These changes have a large impact on the distribution of the SAH centre location (see Fig. 5). This emphasises the impact of model properties on the SAH centre location. Since some of the features described above are only shown by NCEP-1 and NCEP-2 the importance of the data assimilation scheme (e.g. inclusion of TOVS and ATOVS temperature profiles for NCEP-1 and NCEP-2 vs. radiance data directly for the other reanalyses) might be inferred. However, this could also be related to the closeness of the underlying model. During the time period 2004-2013, for which advanced observational data, which were not included in NCEP-1 and NCEP-2, are available, similar distributions for daily and pentad data are found. Together with the distribution presented in Fig. 1 for the period 1980-1994, this indicates that the time period chosen does not influence our results qualitatively. This in turn brings us to the hypothesis that the transition between different observational data sets, which are included in the reanalyses, are of minor importance.

Wright and Fueglistaler (2013) have found large differences in the climatologies of diabatic heating rates among different reanalyses. These diabatic heating rate differences (and connected differences on shorter timescales) can be expected to have an impact on the distributions of the SAH centre location (on daily and pentad basis) with respect to the various reanalyses. The most prominent difference in the distribution of the SAH centre location is that the clear bimodality on short timescales found in previous studies (mostly based on NCEP-1 data) is not visible in most recent reanalyses.

We cannot answer the question of which reanalysis represents the reality best. Nevertheless, the fact that modern reanalyses do not produce the bimodality of the SAH centre location with respect to daily, pentad and seasonal data strongly suggests that the bimodality found on these timescales using NCEP-1 data is an artefact of this particular reanalysis.

Previous studies that address the bimodality of the SAH have mostly focused on the $100 \mathrm{hPa}$ level (see Table 2). To see how robust our results are, we employed ERA-I on the $395 \mathrm{~K}$ level. The SAH centre location was defined as the maximum of the Montgomery stream function along the ridgeline. We found that the PDFs of the SAH centre location with respect to daily and monthly data are similar to ERA-I on $100 \mathrm{hPa}$. For the seasonal mean data we have found that the distribution changes in favour of the TM and IM, i.e. for seasonal data 12,10 and 14 years are located in the IP, midregion and $\mathrm{TP}$ region respectively.

To assess what drives the variability of the SAH we show the movement of the SAH centre and the temporal evolution of geopotential at $100 \mathrm{hPa}$ from ERA-I. We find that geopotential often moves to the west and that less regular shedding occurs to the east of the SAH centre. The mean seasonal evolution of convection (in the South Asian tropical region, here $70-130^{\circ} \mathrm{E} \times 15-30^{\circ} \mathrm{N}$ ) and mean seasonal location of the SAH centre as diagnosed by ERA-I show a clear connection (see Figs. 11 and 12): as the region of low OLR and strong precipitation (deep convective region) extends northwestward during the build-up phase of the SAH, the SAH and its centre move north-westward as well. Once the region of strong convection withdraws south-eastward, the SAH centre follows accordingly. This is in agreement with Gill (1980) and the climatologies of geopotential height and OLR during JJA shown in Figs. 4 and 10 and was discussed based on monthly data for the retreat phase of the SAH in Lau et al. (1988). The smoothed mean seasonal movement of the SAH as diagnosed from NCEP-1 behaves accordingly, but with a slightly smaller longitudinal range of approximately $\sim 25^{\circ}$ compared to $\sim 30^{\circ}$ for ERA-I.

A time lag analysis, linking convective activity in the tropics and the evolution of geopotential at $100 \mathrm{hPa}$ on subseasonal timescales, shows that the instantaneous response of the geopotential field to convective activity is located on the western edge of the forcing region, again in agreement with results of Gill (1980). Overall, the evolution of geopotential and its connection to OLR (convection) is in agreement with findings based on MERRA data from Garny and Randel (2013), who link divergence associated with deep convection to the evolution of the area of low potential vorticity (PV) at $360 \mathrm{~K}$ (see their Figs. 6 and 8). When performing the time lag analysis with an averaging area of OLR, which extends farther to the north, we found weaker anticorrelations. Furthermore, when averaging OLR over the TP (approximately $70-105^{\circ} \mathrm{E} \times 30-40^{\circ} \mathrm{N}$ ) only, we get positive correlations of 
OLR with geopotential height located over the TP (in contrast to negative correlations, which associate reduced OLR with increased convection and strengthening of the SAH). Two possible reasons for this are (1) the SAH is not powered but maybe fed by the convection over the TP with respect to trace gases (Heath and Fuelberg, 2014). (2) (Low) OLR in this region is not a reliable measure for convection due to the height of the TP. This might be enhanced by sampling biases due to the sun-synchronous orbit of the NOAA satellites. These biases are more important over land because convection has a stronger diurnal cycle over land than over sea (Liu and Zipser, 2008).

Composites of eastern and western summers during 19792013 and corresponding anomalies of the vertical velocities at $100 \mathrm{hPa}$ indicate the possible connection of a more eastward or westward location of the $\mathrm{SAH}$ with altered stratosphere-troposphere exchange in the monsoon region. The analysis of composite differences of OLR and precipitation for western and eastern summers (months), based on the location of the SAH centre, yields anomalies of convection and precipitation between these summers (months). There is notably more convection over the Arabian Sea (and India) and consequently more precipitation over India when the SAH centre is located more westward. In contrast, during eastern summers and months there is more convective activity and stronger precipitation over the western Pacific. Additionally, during the western summers and months negative surface temperature anomalies can be found over India, which is probably connected to stronger precipitation. Furthermore, in the monthly analysis we have found that these signatures mostly come from the months of June and July.

As the composite analysis of convection and precipitation, with respect to seasonal mean and monthly mean data, suggests a connection between the SAH location and the ISM (measured by IMD's AIRI), we display the relationship of the seasonal SAH centre location (from ERA-I) and the seasonal AIRI in Fig. 16a. Figure 16b shows the correlation coefficients of the location of the SAH centre with the AIRI over the time period of June to August 1979-2013 for the seven reanalyses (1979-2010 for CFSR). For the calculation of the monthly mean correlation coefficients the data were deseasonalised (i.e. multiannual monthly means were subtracted from the SAH location and the AIRI time series).

All reanalyses show stronger anticorrelations based on seasonal mean than on monthly mean data, except for CFSR and NCEP-2. The latter does not produce a significant anticorrelation on the seasonal timescale. Moreover, for the separate months the connection between the SAH location and the ISM in June and July is stronger than in August (except for JRA-25, June -0.32 vs. -0.33 in August) and gets insignificant, on the $10 \%$ level, for CFSR, JRA-55, MERRA, NCEP-1 and NCEP-2. This is in agreement with the findings from the composite analysis.

The Asian monsoon system and especially the ISM is influenced strongly by ENSO (see, e.g., Mooley and

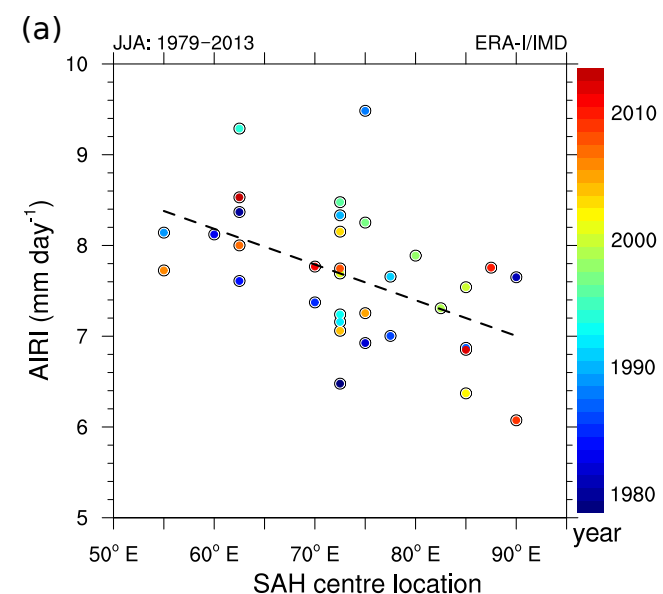

(b)

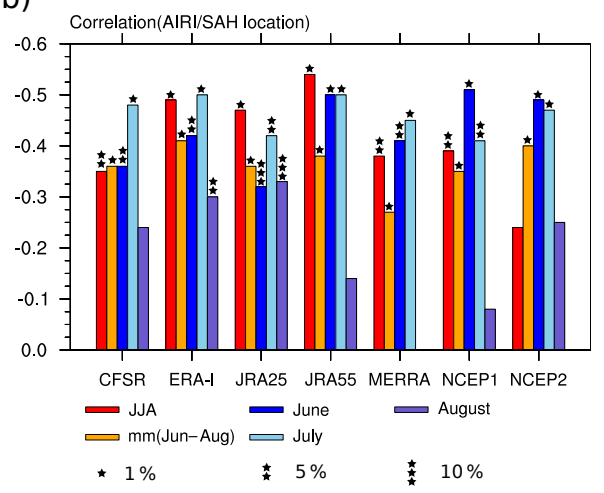

Figure 16. (a) Scatter plot of AIRI and the SAH location from ERA-I based on JJA data during 1979-2013 (years are colour coded). Black line indicates the regression line. (b) Correlation of AIRI with the longitudinal location of the SAH centre based on seasonal (red columns) and monthly mean (orange columns) data during June to August 1979-2013 (1979-2010 for CFSR) for the seven reanalyses. For monthly mean data the time series was deseasonalised (i.e. multiannual June, July or August values were subtracted). Blue colours indicate the correlation for the months June, July and August separately. Stars indicate the respective significance level.

Parthasarathy, 1983). Hence, we analysed the impact of ENSO on the connection between seasonal SAH centre location and ISM by calculating partial correlations between the SAH's longitudinal location from ERA-I and the AIRI index with respect to the seasonal Niño 3.4 index from CPC. Partial correlations were calculated with respect to the lagged seasonal Niño 3.4 starting with DJF before the summer monsoon and ending with NDJ following the monsoon period. These partial correlations were ranging from -0.44 to -0.51 , which is comparable to the simple correlation coefficient between the two indices. The lagged correlations between the SAH's location and Niño 3.4 were below 0.1 and not significant. 
The relationship between the ISM and the SAH is also supported by the findings of Wei et al. (2014, 2015), who linked the west-east and north-west to south-east displacement of the SAH on interannual timescales with the strength of the ISM. In detail they used two indices, the $\mathrm{SAHI}_{14}$ and the $\mathrm{SAHI}_{15}$ (see caption of Fig. 14), as given by geopotential from ERA40 on $200 \mathrm{hPa}$ (based on JJA data during 19582002), and found correlation coefficients of -0.49 for the $\mathrm{SAHI}_{14}$ and -0.64 between the $\mathrm{SAHI}_{15}$ and the rainfall over India (note that a more positive SAHI corresponds to a more eastward location of the SAH). We calculated the correlation of the $\mathrm{SAHI}_{14}$ and the SAHI 15 for ERA-I geopotential at $100 \mathrm{hPa}$ and AIRI from the IMD as -0.57 and -0.61 respectively. Additionally, Wei et al. (2014) performed idealised model studies and showed the importance of latent heat release over India to the location of the SAH on interannual timescales. Wei et al. (2014) also address the possible influence of ENSO on the SAH's longitudinal location and come to a similar conclusion that ENSO does not play a major role for western-eastern shifts of the SAH on interannual timescales.

However, in contrast to the findings of Wei et al. (2015), who identify an opposing heating or cooling source over the Yangtze River valley using GPCC data from 1958 to 2002, we do not find a significant connection between rainfall in this region and the location of the $\mathrm{SAH}$, but rather with convective activity over the western Pacific. The corresponding excess or deficit precipitation over the western Pacific was also found in some of the AOGCM-based precipitation composites, which were presented in Zhou et al. (2006) (their Fig. 4).

The composite difference of OLR based on daily data shows results similar to the seasonal and monthly data. To check how robust the signatures are, we have built composites based on the SAH centre location at $100 \mathrm{hPa}$ from NCEP1. In general, the results match those from when the splitting is performed based on ERA-I. Especially for the daily (1344 west, 1305 east) and monthly (35 west, 39 east) mean data the results match well. For the seasonal data (9 west, 10 east) the signatures in OLR and precipitation over India are shifted farther towards the southern slopes of the Himalayas.

As plateau heating has been discussed as a driver for the SAH shift (e.g. Zhang et al., 2002; Liu et al., 2007), we have performed the composite analysis on reanalysis surface temperature data for ERA-I and NCEP-1 (not shown). The results show that during western periods surface temperatures are usually lower (up to $-1.25 \mathrm{~K}$ ) over India, likely associated with heavier rainfall in this region. With respect to the IP (TP), positive (negative) anomalies in surface temperatures get more pronounced on shorter timescales. This is especially the case for ERA-I data, where only the composite based on daily data shows a clear and significant negative anomaly over the TP during western phases, whereas for NCEP-1 data the TP and IP anomalies are strong regardless of the timescale. This might be hinting that the significance of heating associated with the two plateaus is of more importance on shorter timescales and in NCEP-1 compared to ERA-I data.

The drawback of using reanalysis surface temperature data, especially in the TP (and probably IP) region where observational data are scarce, is that this variable is strongly influenced by the model itself (at least for NCEP-1 see Kalnay et al., 1996). Hence, the signatures in surface temperatures over the TP might not be reliable and thus reflect the models' connection of surface temperature over the TP with the location of the SAH.

\section{Conclusion}

In this study the movement and drivers of the SAH during the period 1979-2014 are investigated using observational and reanalysis data. Special attention is brought to the subject of bimodality, i.e. the two preferred modes of the SAH's centre location over the Tibetan and Iranian plateaus.

We find that bimodality with respect to daily, pentad and seasonal data at $100 \mathrm{hPa}$ is only found in NCEP-1 and NCEP2; however, they are not consistent with each other. Although we cannot rule out that NCEP-1 or NCEP-2 simulate the distribution of the SAH centre correctly, the other reanalyses including most recent ones (e.g. ERA-I and JRA-55) - do not support the notion of bimodality as two designated centres of activity. This is of special interest because a couple of studies have conducted analyses based on this concept. Thus, it might be useful to investigate if their findings are affected when more recent reanalyses are being used. Furthermore, it might limit the conclusions drawn from these studies, i.e. the drivers associated with the two modes might reflect the model properties rather than the actual atmospheric situation and thus might vary from reanalysis to reanalysis. Finally, using a more recent reanalysis might enhance results found in composite differences, e.g. with respect to satellite-measured trace gases as in Yan et al. (2011).

With respect to the drivers of the SAH, we find that shifts in convection are a main cause for the shift in the location of the SAH (on various scales): we connected the mean seasonal evolution of the SAH to the seasonal cycle of convection in the tropical region adjacent to the SAH. A modified extension of the composite analysis performed in Wei et al. $(2014,2015)$ showed that the ISM and convection over the western Pacific are related to the longitudinal position of the SAH centre. Hence, the location of the SAH might be related to different boundary layer source regions and in turn affect consequent transport (maybe into the stratosphere; see Fig. 14).

We note that on top of the influence through the location of convection, internal variability - i.e. instability of the anticyclone and subsequent westward movement or splitting (Hsu and Plumb, 2000; Popovic and Plumb, 2001) - plus exter- 
nal forcing (described by Dethof et al., 1999) influence the location of the SAH on the synoptic timescales. Additional influences from the orography and heating of the TP and IP might also modulate the location of the SAH (e.g. Zhang et al., 2002; Liu et al., 2007, and references therein). The relative importance of the thermal forcing of the TP and convection in the South Asian region on the synoptic movement of the SAH is still an open point and difficult to evaluate from reanalysis and observational data only.

\section{Data availability}

We acknowledge the institutions listed in Table 1 for the production and dissemination of reanalysis data.

Acknowledgements. We thank William Randel, KlausDirk Gottschaldt and Helmut Ziereis for their helpful comments on the paper. The research leading to these results received funding from the European Community's Seventh Framework Programme (FP7/2007-2013) under grant agreement no. 603557.

The article processing charges for this open-access

publication were covered by the Research

Centre of the Helmholtz Association.

Edited by: G. Stiller

Reviewed by: three anonymous referees

\section{References}

Adler, R., Huffman, G., Chang, A., Ferraro, R., Xie, P., Janowiak, J., Rudolf, B., Schneider, U., Curtis, S., Bolvin, D., Gruber, A., Susskind, J., and Arkin, P.: The Version 2 Global Precipitation Climatology Project (GPCP) Monthly Precipitation Analysis (1979-Present), J. Hydrometeorol., 4, 1147-1167, 2003.

Chirkov, M., Stiller, G. P., Laeng, A., Kellmann, S., von Clarmann, T., Boone, C. D., Elkins, J. W., Engel, A., Glatthor, N., Grabowski, U., Harth, C. M., Kiefer, M., Kolonjari, F., Krummel, P. B., Linden, A., Lunder, C. R., Miller, B. R., Montzka, S. A., Mühle, J., O’Doherty, S., Orphal, J., Prinn, R. G., Toon, G., Vollmer, M. K., Walker, K. A., Weiss, R. F., Wiegele, A., and Young, D.: Global HCFC-22 measurements with MIPAS: retrieval, validation, global distribution and its evolution over 2005-2012, Atmos. Chem. Phys., 16, 3345-3368, doi:10.5194/acp-16-3345-2016, 2016.

Dee, D. P., Uppala, S. M., Simmons, A. J., Berrisford, P., Poli, P., Kobayashi, S., Andrae, U., Balmaseda, M. A., Balsamo, G., Bauer, P., Bechtold, P., Beljaars, A. C. M., van de Berg, L., Bidlot, J., Bormann, N., Delsol, C., Dragani, R., Fuentes, M., Geer, A. J., Haimberger, L., Healy, S. B., Hersbach, H., Hólm, E. V., Isaksen, L., Kållberg, P., Köhler, M., Matricardi, M., McNally, A. P., Monge-Sanz, B. M., Morcrette, J.-J., Park, B.-K., Peubey, C., de Rosnay, P., Tavolato, C., Thépaut, J.-N., and Vitart, F.: The ERA-Interim reanalysis: configuration and performance of the data assimilation system, Q. J. Roy. Meteor. Soc., 137, 553-597, doi:10.1002/qj.828, 2011.
Dethof, A., Oneill, A., Slingo, J. M., and Smit, H. G. J.: A mechanism for moistening the lower stratosphere involving the Asian summer monsoon, Q. J. Roy. Meteor. Soc., 125, 1079-1106, doi:10.1256/smsqj.55601, 1999.

ESMVal: Earth System Model Validation, available at: http://www. pa.op.dlr.de/ESMVal/index.html (last access: 6 April 2016), 2012.

Garny, H. and Randel, W. J.: Dynamic variability of the Asian monsoon anticyclone observed in potential vorticity and correlations with tracer distributions, J. Geophys. Res.-Atmos., 118, 1342113433, doi:10.1002/2013JD020908, 2013.

Gill, A. E.: Some simple solutions for heat-induced tropical circulation, Q. J. Roy. Meteor. Soc., 106, 447-462, doi:10.1002/qj.49710644905, 1980.

Heath, N. K. and Fuelberg, H. E.: Using a WRF simulation to examine regions where convection impacts the Asian summer monsoon anticyclone, Atmos. Chem. Phys., 14, 2055-2070, doi:10.5194/acp-14-2055-2014, 2014.

Hoskins, B. J. and Rodwell, M. J.: A Model of the Asian Summer Monsoon. Part I: The Global Scale, J. Atmos. Sci., 52, 1329-1340, doi:10.1175/15200469(1995)052<1329:AMOTAS>2.0.CO;2, 1995.

Hsu, C. J. and Plumb, R. A.: Nonaxisymmetric Thermally Driven Circulations and Upper-Tropospheric Monsoon Dynamics, J. Atmos. Sci., 57, 1255-1276, doi:10.1175/15200469(2000)057<1255:NTDCAU>2.0.CO;2, 2000.

Huang, B., Banzon, V. F., Freeman, E., Lawrimore, J., Liu, W., Peterson, T. C., Smith, T. M., Thorne, P. W., Woodruff, S. D., and Zhang, H.-M.: Extended Reconstructed Sea Surface Temperature Version 4 (ERSST.v4). Part I: Upgrades and Intercomparisons, J. Climate, 28, 911-930, doi:10.1175/JCLI-D-14-00006.1, 2015.

Huang, B., Thorne, P. W., Smith, T. M., Liu, W., Lawrimore, J., Banzon, V. F., Zhang, H.-M., Peterson, T. C., and Menne, M.: Further Exploring and Quantifying Uncertainties for Extended Reconstructed Sea Surface Temperature (ERSST) Version 4 (v4), J. Climate, 29, 3119-3142, doi:10.1175/JCLI-D-15-0430.1, 2016.

Huffman, G. J., Adler, R. F., Morrissey, M. M., Bolvin, D. T., Curtis, S., Joyce, R., McGavock, B., and Susskind, J.: Global Precipitation at One-Degree Daily Resolution from Multisatellite Observations, J. Hydrometeorol., 2, 36-50, doi:10.1175/15257541(2001)002<0036:GPAODD>2.0.CO;2, 2001.

Kalnay, E., Kanamitsu, M., Kistler, R., Collins, W., Deaven, D., Gandin, L., Iredell, M., Saha, S., White, G., Woollen, J., Zhu, Y., Leetmaa, A., Reynolds, R., Chelliah, M., Ebisuzaki, W., Higgins, W., Janowiak, J., Mo, K. C., Ropelewski, C., Wang, J., Jenne, R., and Joseph, D.: The NCEP/NCAR 40-Year Reanalysis Project, B. Am. Meteorol. Soc., 77, 437-471, doi:10.1175/15200477(1996)077<0437:TNYRP>2.0.CO;2, 1996.

Kanamitsu, M., Ebisuzaki, W., Woollen, J., Yang, S.-K., Hnilo, J. J., Fiorino, M., and Potter, G. L.: NCEP-DOE AMIPII Reanalysis (R-2), B. Am. Meteorol. Soc., 83, 1631-1643, doi:10.1175/BAMS-83-11-1631, 2002.

Kobayashi, S., Ota, Y., Harada, Y., Ebita, A., Moriya, M., Onoda, H., Onogi, K., Kamahori, H., Kobayashi, C., Endo, H., Miyaoka, K., and Takahashi, K.: The JRA-55 Reanalysis: General Specifications and Basic Characteristics, J. Meteorol. Soc. Jpn., 93, 5-48, doi:10.2151/jmsj.2015-001, 2015.

Lau, K.-M., Yang, G. J., and Shen, S. H.: Seasonal and Intraseasonal Climatology of Summer Monsoon Rainfall over 
Eeat Asia, Mon. Weather Rev., 116, 18-37, doi:10.1175/15200493(1988)116<0018:SAICOS>2.0.CO;2, 1988.

Li, Q., Jiang, J. H., Wu, D. L., Read, W. G., Livesey, N. J., Waters, J. W., Zhang, Y., Wang, B., Filipiak, M. J., Davis, C. P., Turquety, S., Wu, S., Park, R. J., Yantosca, R. M., and Jacob, D. J.: Convective outflow of South Asian pollution: A global CTM simulation compared with EOS MLS observations, Geophys. Res. Lett., 32, L14826, doi:10.1029/2005GL022762, 2005.

Liebman, B. and Smith, C.: Description of a Complete (Interpolated) Outgoing Longwave Radiation Dataset, B. Am. Meteorol. Soc., 77, 1275-1277, 1996.

Liu, C. and Zipser, E. J.: Diurnal cycles of precipitation, clouds, and lightning in the tropics from 9 years of TRMM observations, Geophys. Res. Lett., 35, L04819, doi:10.1029/2007GL032437, 2008

Liu, W., Huang, B., Thorne, P. W., Banzon, V. F., Zhang, H.M., Freeman, E., Lawrimore, J., Peterson, T. C., Smith, T. M., and Woodruff, S. D.: Extended Reconstructed Sea Surface Temperature Version 4 (ERSST.v4): Part II. Parametric and Structural Uncertainty Estimations, J. Climate, 28, 931-951, doi:10.1175/JCLI-D-14-00007.1, 2015.

Liu, Y., Hoskins, B., and Blackburn, M.: Impact of Tibetan Orography and Heating on the Summer Flow over Asia, J. Meteorol. Soc. Jpn., 85B, 1-19, doi:10.2151/jmsj.85B.1, 2007.

Mason, R. B. and Anderson, C. E.: The development and decay of the $100-\mathrm{mb}$. summertime anticyclone over southern Asia, Mon. Weather Rev., 91, 3-12, doi:10.1175/15200493(1963)091<0003:TDADOT>2.3.CO;2, 1963.

Mooley, D. A. and Parthasarathy, B.: Indian summer monsoon and El Nino, pure and applied geophysics, 121, 339-352, doi:10.1007/BF02590143, 1983.

Müller, S., Hoor, P., Bozem, H., Gute, E., Vogel, B., Zahn, A., Bönisch, H., Keber, T., Krämer, M., Rolf, C., Riese, M., Schlager, H., and Engel, A.: Impact of the Asian monsoon on the extratropical lower stratosphere: trace gas observations during TACTS over Europe 2012, Atmos. Chem. Phys., 16, 10573-10589, doi:10.5194/acp-16-10573-2016, 2016.

OMO: Oxidation Mechanism Observations, available at: http:// www.mpic.de/en/research/collaborative-projects/halo/omo.html (last access: 6 April 2016), 2015.

Onogi, K., Tsutsui, J., Koide, H., Sakamoto, M., Kobayashi, S., Hatsushika, H., Matsumoto, T., Yamazaki, N., Kamahori, H., Takashi, K., Kadokura, S., Wada, K., Kato, K., Oyama, R., Ose, T., Mannoji, N., and Taira, R.: The JRA-25 Reanalysis, J. Meteorol. Soc. Jpn., 85, 369-432, doi:10.2151/jmsj.85.369, 2007.

Park, M., Randel, W. J., Emmons, L. K., and Livesey, N. J.: Transport pathways of carbon monoxide in the Asian summer monsoon diagnosed from Model of Ozone and Related Tracers (MOZART), J. Geophys. Res.-Atmos., 114, D08303, doi:10.1029/2008JD010621, 2009.

Ploeger, F., Gottschling, C., Griessbach, S., Grooß, J.-U., Guenther, G., Konopka, P., Müller, R., Riese, M., Stroh, F., Tao, M., Ungermann, J., Vogel, B., and von Hobe, M.: A potential vorticitybased determination of the transport barrier in the Asian summer monsoon anticyclone, Atmos. Chem. Phys., 15, 13145-13159, doi:10.5194/acp-15-13145-2015, 2015.

Popovic, J. M. and Plumb, R. A.: Eddy Shedding from the Upper-Tropospheric Asian Monsoon Anticy- clone, J. Atmos. Sci., 58, 93-104, doi:10.1175/15200469(2001)058<0093:ESFTUT>2.0.CO;2, 2001.

Qian, Y., Zhang, Q., Yao, Y., and Zhang, X.: Seasonal variation and heat preference of the south asia high, Adv. Atmos. Sci., 19, 821836, doi:10.1007/s00376-002-0047-3, 2002.

Randel, W. J. and Park, M.: Deep convective influence on the Asian summer monsoon anticyclone and associated tracer variability observed with Atmospheric Infrared Sounder (AIRS), J. Geophys. Res., 111, D12314, doi:10.1029/2005JD006490, 2006.

Randel, W. J., Park, M., Emmons, L., Kinnison, D., Bernath, P., Walker, K. A., Boone, C., and Pumphrey, H.: Asian Monsoon Transport of Pollution to the Stratosphere, Science, 328, 611613, doi:10.1126/science.1182274, 2010.

Rienecker, M. M., Suarez, M. J., Gelaro, R., Todling, R., Bacmeister, J., Liu, E., Bosilovich, M. G., Schubert, S. D., Takacs, L., Kim, G.-K., Bloom, S., Chen, J., Collins, D., Conaty, A., da Silva, A., Gu, W., Joiner, J., Koster, R. D., Lucchesi, R., Molod, A., Owens, T., Pawson, S., Pegion, P., Redder, C. R., Reichle, R., Robertson, F. R., Ruddick, A. G., Sienkiewicz, M., and Woollen, J.: MERRA: NASA's Modern-Era Retrospective Analysis for Research and Applications, J. Climate, 24, 3624-3648, doi:10.1175/JCLI-D-11-00015.1, 2011.

Rodwell, M. J. and Hoskins, B. J.: A Model of the Asian Summer Monsoon. Part II: Cross-Equatorial Flow and PV Behavior, J. Atmos. Sci., 52, 1341-1356, doi:10.1175/15200469(1995)052<1341:AMOTAS>2.0.CO;2, 1995.

Rodwell, M. J. and Hoskins, B. J.: Monsoons and the dynamics of deserts, Q. J. Roy. Meteor. Soc., 122, 1385-1404, doi:10.1002/qj.49712253408, 1996.

Saha, S., Moorthi, S., Pan, H.-L., Wu, X., Wang, J., Nadiga, S., Tripp, P., Kistler, R., Woollen, J., Behringer, D., Liu, H., Stokes, D., Grumbine, R., Gayno, G., Wang, J., Hou, Y.-T., Chuang, H.Y., Juang, H.-M. H., Sela, J., Iredell, M., Treadon, R., Kleist, D., Delst, P. V., Keyser, D., Derber, J., Ek, M., Meng, J., Wei, H., Yang, R., Lord, S., Dool, H. V. D., Kumar, A., Wang, W., Long, C., Chelliah, M., Xue, Y., Huang, B., Schemm, J.-K., Ebisuzaki, W., Lin, R., Xie, P., Chen, M., Zhou, S., Higgins, W., Zou, C.-Z., Liu, Q., Chen, Y., Han, Y., Cucurull, L., Reynolds, R. W., Rutledge, G., and Goldberg, M.: The NCEP Climate Forecast System Reanalysis, B. Am. Meteorol. Soc., 91, 1015-1057, doi:10.1175/2010BAMS3001.1, 2010.

StratoClim: Stratospheric and upper tropospheric processes for better climate predictions, available at: http://www.stratoclim.org (last access: 6 April 2016), 2016/2017.

Vogel, B., Günther, G., Müller, R., Grooß, J.-U., Hoor, P., Krämer, M., Müller, S., Zahn, A., and Riese, M.: Fast transport from Southeast Asia boundary layer sources to northern Europe: rapid uplift in typhoons and eastward eddy shedding of the Asian monsoon anticyclone, Atmos. Chem. Phys., 14, 12745-12762, doi:10.5194/acp-14-12745-2014, 2014.

Vogel, B., Günther, G., Müller, R., Grooß, J.-U., and Riese, M.: Impact of different Asian source regions on the composition of the Asian monsoon anticyclone and of the extratropical lowermost stratosphere, Atmos. Chem. Phys., 15, 13699-13716, doi:10.5194/acp-15-13699-2015, 2015.

Vogel, B., Günther, G., Müller, R., Grooß, J.-U., Afchine, A., Bozem, H., Hoor, P., Krämer, M., Müller, S., Riese, M., Rolf, C., Spelten, N., Stiller, G. P., Ungermann, J., and Zahn, A.: Longrange transport pathways of tropospheric source gases origi- 
nating in Asia into the northern lower stratosphere during the Asian monsoon season 2012, Atmos. Chem. Phys. Discuss., doi:10.5194/acp-2016-463, in review, 2016.

Wei, W., Zhang, R., Wen, M., Rong, X., and Li, T.: Impact of Indian summer monsoon on the South Asian High and its influence on summer rainfall over China, Clim. Dynam., 43, 1257-1269, doi:10.1007/s00382-013-1938-y, 2014.

Wei, W., Zhang, R., Wen, M., Kim, B.-J., and Nam, J.-C.: Interannual Variation of the South Asian High and Its Relation with Indian and East Asian Summer Monsoon Rainfall, J. Climate, 28, 2623-2634, doi:10.1175/JCLI-D-14-00454.1, 2015.

Wright, J. S. and Fueglistaler, S.: Large differences in reanalyses of diabatic heating in the tropical upper troposphere and lower stratosphere, Atmos. Chem. Phys., 13, 9565-9576, doi:10.5194/acp-13-9565-2013, 2013.

Wu, G., Zhang, Q., Duan, A., and Mao, J.: Thermal-Dynamical effects of the Tibetan Plateau on the East Asian Monsoon, in: Monsoon Asia Integrated Regional Study on Global Change Changes in the Human-Monsoon System of East Asia in the Context of Global Change, edited by: Fu, C., Freney, J., and Stewart, J., vol. 1, 9-22, World Scientific Publishing Company, doi:10.1142/9789812832429_0002, 2008.

$\mathrm{Xu}, \mathrm{Z}$. and Zhang, Y.: Effects of the Tibetan Plateau on the Climate of China, in: Regional Climate Studies of China, edited by: Fu, C., Jiang, Z., Guan, Z., He, J., and Xu, Z., 219-270, Springer Berlin Heidelberg, doi:10.1007/978-3-540-79242-0, 2008.

Yan, R., Bian, J., and Fan, Q.: The Impact of the South Asia High Bimodality on the Chemical Composition of the Upper Troposphere and Lower Stratosphere, Atmospheric and Oceanic Science Letters, 4, 229-234, doi:10.1080/16742834.2011.11446934, 2011.
Yanai, M. and Wu, G.: Effects of the Tibetan Plateau, in: The Asian Monsoon, edited by: Wang, B., 513-549, Springer Berlin Heidelberg, doi:10.1007/3-540-37722-0, 2006.

Yihui, D. and Chan, L. J. C.: The East Asian summer monsoon: an overview, Meteorol. Atmos. Phys., 89, 117-142, doi:10.1007/s00703-005-0125-z, 2005.

Zarrin, A., Ghaemi, H., Azadi, M., and Farajzadeh, M.: The spatial pattern of summertime subtropical anticyclones over Asia and Africa: A climatological review, Int. J. Climatol., 30, 159-173, doi:10.1002/joc.1879, 2010.

Zhang, L. and Zhi, X.: Longitudinal Oscillations of the South Asian High and the Subtropical Western Pacific High during boreal summer, in: Advances in Geosciences, edited by: Ip, W.-H. and Oh, J. H., vol. 16, 93-107, World Scientific Publishing Company, doi:10.1142/9789812838100_0009, 2010.

Zhang, Q., Wu, G., and Qian, Y.: The Bimodality of the $100 \mathrm{hPa}$ South Asia High and its Relationship to the Climate Anomaly over East Asia in Summer, J. Meteorol. Soc. Jpn., 80, 733-744, doi:10.2151/jmsj.80.733, 2002.

Zhou, N., Yu, Y., and Qian, Y.: Simulations of the $100 \mathrm{hPa}$ South Asian High and precipitation over East Asia with IPCC coupled GCMs, Adv. Atmos. Sci., 23, 375-390, doi:10.1007/s00376006-0375-9, 2006.

Zhou, N., Yu, Y., and Qian, Y.: Bimodality of the South Asia High simulated by coupled models, Adv. Atmos. Sci., 26, 1226-1234, doi:10.1007/s00376-009-7219-3, 2009. 